\title{
Energy transfer process in highly photoluminescent binuclear hydrocinnamate of europium, terbium and gadolinium containing 1,10-phenanthroline as ancillary ligand
}

\author{
Lippy F. Marques ${ }^{\mathrm{a}, *}$, Alexandre Cuin ${ }^{\mathrm{b}}$, Gustavo S.G. de Carvalho ${ }^{\mathrm{b}}$, Molíria V. dos Santos ${ }^{\mathrm{c}}$, \\ Sidney J.L. Ribeiro ${ }^{\mathrm{c}}$, Flávia C. Machado ${ }^{\mathrm{b}}$ \\ a Instituto de Química, Universidade do Estado do Rio de Janeiro, Rio de Janeiro 20550-013, Brazil \\ ${ }^{\mathrm{b}}$ Departamento de Química-ICE, Universidade Federal de Juiz de Fora, Juiz de Fora, MG 36036-330 Brazil \\ ${ }^{\mathrm{c}}$ Instituto de Química, Universidade Estadual Paulista Júlio de Mesquita Filho, UNESP, Araraquara, SP 14801-970, Brazil
}

\section{A R T I C L E I N F O}

\section{Article history:}

Received 14 September 2015

Received in revised form 3 November 2015

Accepted 5 November 2015

Available online 14 November 2015

\section{Keywords:}

Hydrocinnamic acid

Photoluminescence studies

Nitrogen ligands

\begin{abstract}
A B S T R A C T
New binuclear lanthanide (III) complexes of general formula $\left[\operatorname{Ln}_{2}(\text { hcin })_{6}(\text { phen })_{2}\right]$ (where $\mathrm{Ln}=\mathrm{Eu} \mathrm{1;} \mathrm{Gd} \mathrm{2;}$ Tb 3; hcin = hydrocinnamate anion; phen =1,10-phenanthroline) were synthesized and fully characterized by elemental analysis, vibrational spectroscopy (infrared and Raman), thermal analysis (TGA/ DTA), $\mathrm{CP} / \mathrm{MAS}{ }^{13} \mathrm{C}$ NMR and powder X-ray diffraction. The crystal description based on powder X-ray diffraction data reveals that all compounds are isostructural and that each lanthanide ion is nine coordinated by oxygen and nitrogen atoms to form distorted tricapped trigonal-prismatic coordination polyhedron. The photoluminescence behavior was studied based on the excitation and emission spectra and luminescence decay curves. The emission spectra of $\mathrm{Eu}(\mathrm{III})$ and $\mathrm{Tb}(\mathrm{III})$ complexes are composed of intense and typical red and green emissions, respectively. Phosphorescence data of Gd(III) complex showed that the triplet states $\left(\mathrm{T}_{1}\right)$ of ligands have higher energy than the main emitting states of $\mathrm{Eu}(\mathrm{III})$ and $\mathrm{Tb}(\mathrm{III})$ indicating the possibility of intramolecular energy transfer for these metal ions. To elucidate the energy transfer process in the Eu(III) complex, spectroscopic properties as $\Omega_{\lambda}$ intensity parameters $(\lambda=2$ and 4 ), radiative $\left(A_{\text {rad }}\right)$ and nonradiative $\left(A_{\text {nrad }}\right)$ decay rates and quantum efficiency $(\eta)$ of $\left[\mathrm{Eu}_{2}(\text { hcin })_{6}(\text { phen })_{2}\right]$ were determined. Such spectroscopic properties were compared with $\left[\mathrm{Eu}_{2}(\mathrm{hcin})_{6}(\mathrm{bpy})_{2}\right]$ complex properties recently reported. The high emission quantum efficiency $(\eta=72 \%)$ for Eu(III) complex 1 showed that it is a potential candidate as emitter in photonic systems.
\end{abstract}

(c) 2015 Elsevier B.V. All rights reserved.

\section{Introduction}

The chemistry and spectroscopy of lanthanide ions ( $\operatorname{Ln}(\mathrm{III}))$ differ considerably from $d$-shell transition metal ions. The shielding of $4 f$ orbitals by the filled $5 p^{6} 6 s^{2}$ subshells results in special optical features of lanthanide ions such as the minimal perturbation by the external field generated by the ligands [1,2]. For example, lanthanide compounds are characterized as exhibiting narrow linelike emissions of optical pure colors. All lanthanide ions, except $\mathrm{La}$ (III) and $\mathrm{Lu}(\mathrm{III})$ are luminescent, but the investigation of $\mathrm{Eu}(\mathrm{III})$ and $\mathrm{Tb}(\mathrm{III})$ ions luminescence properties has a special relevance because their specific strong red $(\sim 615 \mathrm{~nm})$ and green $(\sim 540 \mathrm{~nm})$ emission, and also the long lifetimes of the excited ${ }^{5} \mathrm{D}_{0}$ and ${ }^{5} \mathrm{D}_{4}$ states, respectively. In this case, it is not surprising that

\footnotetext{
* Corresponding author. Tel.: +55 2123340563.

E-mail address: lippymarquesuerj@gmail.com (L.F. Marques).
}

these compounds are currently applied in different fields, ranging from light emitting diodes to enable full-color and low-cost to fluoroimmunoassay reagents [3-5]. The search of new lanthanide complexes has been an active area of research in coordination chemistry mainly due to the possibility of designing novel photoluminescent materials [6-8]. However, the use of some lanthanide ions systems with direct absorption of the $f$ excited states is very inefficient because the $f-f$ transitions are parity forbidden, resulting in very low absorption coefficients. In order to overcome this drawback, suitable chromophores have been employed as antennas (or sensitizers) that have the capability of transferring energy indirectly to lanthanide ions [9]. In general, the choice of the ligand is important for the emission efficiency and in particular several chromophoric antenna ligands, like $\beta$-diketonate $[10,11]$ and carboxylate ligands [12-14], collect the photons and transfer their energy towards the lanthanide center which gets indirectly excited and emits light during the relaxation process. In particular, the 
hydrocinnamic acid (Hhcin) or 3-phenylpropanoic acid is an analog of phenylalanine [15] and belongs to the class of phenylpropanoids used as additives in food and pharmaceuticals products [16]. Despite its structural simplicity, there are very few studies of complexes with the hydrocinnamic acid [17-20]. In addition, previous studies show that the emission intensities and fluorescence lifetimes of lanthanide complexes are enhanced after introducing the second organic ligand as 2,2'-bipyridine (bpy) or 1,10-phenanthroline (phen) [20-22]. These ligands act as energy donors and enhance the fluorescence intensities of lanthanide complexes in a so-called "synergistic effect". The introduction of these ligands not only reinforces the fluorescence emission, but also increases the thermal stability and fulfills the coordination numbers of lanthanide complexes. In the present paper we report the one-step synthesis, structural characterization and photoluminescence study of three new binuclear lanthanide (III) complexes $\left[\mathrm{Ln}_{2}\right.$

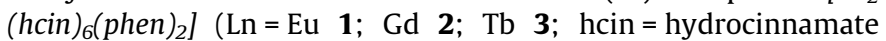
anion; phen =1,10-phenanthroline). Photoluminescence data were obtained from the excitation, emission spectra and luminescence decay curves. The energy transfer process from the excited states of ligands to the intraconfigurational states of the $\operatorname{Ln}(\mathrm{III})$ ions was also investigated. Spectroscopic properties as $\Omega_{\lambda}$ intensity parameters $(\lambda=2$ and 4$)$, radiative $\left(A_{\text {rad }}\right)$ and nonradiative $\left(A_{\text {nrad }}\right)$ decay rates and quantum efficiency $(\eta)$ of $\left[\mathrm{Eu}_{2}(\text { hcin })_{6}(\text { phen })_{2}\right]$ were determined and compared with those for the complex $\left[E u_{2}(h c i n)_{6}(b p y)_{2}\right]$ recently reported [20].

\section{Experimental}

\subsection{Materials and measurements}

All synthetic procedures were performed in air and $\mathrm{TbCl}_{3} \cdot 6 \mathrm{H}_{2} \mathrm{O}$, hydrocinnamic acid (Hhcin) and 1,10-phenanthroline (phen) were obtained either from Aldrich ${ }^{\circledR}$ or Fluka ${ }^{\circledR}$ and used as received. $\mathrm{EuCl}_{3} \cdot 6 \mathrm{H}_{2} \mathrm{O}$ and $\mathrm{GdCl}_{3} \cdot 6 \mathrm{H}_{2} \mathrm{O}$ were prepared by dissolving europium and gadolinium oxide in hydrochloric acid solution and then dried. Elemental analyses for $\mathrm{C}, \mathrm{H}$ and $\mathrm{N}$ were carried out using a PerkinElmer 2400CHN analyzer. FTIR spectra were recorded with a Perkin Elmer (Spectrum One model) FTIR spectrophotometer using $\mathrm{KBr}$ pellets in the wavenumber range of $4000-400 \mathrm{~cm}^{-1}$ with an average of 128 scans and $4 \mathrm{~cm}^{-1}$ of spectral resolution. Fourier-Transform Raman spectroscopy was carried out using a Bruker RFS 100 instrument, $\mathrm{Nd}^{3+} /$ YAG laser operating at $1064 \mathrm{~nm}$ in the near-infrared and CCD detector cooled with liquid $\mathrm{N}_{2}$. Good signal-to-noise ratios were obtained from 2000 scans accumulated over a period of about $30 \mathrm{~min}$, using $4 \mathrm{~cm}^{-1}$ as spectral resolution. Thermal analysis (TG and DTA curves) were obtained on a Shimadzu TG-60 equipment where about $6-10 \mathrm{mg}$ of samples were heated at $10{ }^{\circ} \mathrm{C} / \mathrm{min}$ from room temperature to $800^{\circ} \mathrm{C}$ in a dynamic argon atmosphere (flow rate $=100 \mathrm{~mL} / \mathrm{min}$ ). The $\mathrm{CP} / \mathrm{MAS}{ }^{13} \mathrm{C}$ NMR experiments were performed on a Bruker Avance III HD 300 spectrometer $(7.04 \mathrm{~T})$, operated at a Larmor frequency of $75.00 \mathrm{MHz}$. The analyses were performed on a MAS probe in $\mathrm{ZrO}_{2}$ rotors (and Kel-F caps) of $4 \mathrm{~mm}$. The spectra were obtained using MAS, at a frequency of $10000 \mathrm{~Hz}$, and cross polarization. The chemical shifts were indirectly standardized on a sample of glycine with respect to the carbonyl signal at $176.00 \mathrm{ppm}$ relative to TMS which is the primary standard. The luminescence excitation and emission spectra were recorded using a Jobin-Yvon Model Fluorolog FL3-22 spectrophotometer equipped with a R928 Hamamatsu photomultiplier and $450 \mathrm{~W}$ xenon lamp as excitation source and the spectra were corrected with respect to the Xe lamp intensity and spectrometer response. Measurements of emission decay were performed with the same equipment by using a pulsed Xe ( $3 \mu \mathrm{s}$ bandwidth) source.

\subsection{X-ray powder diffraction data collection and structure determination}

To perform the full powder X-ray diffraction analysis the three polycrystalline lanthanides complexes were gently grounded in an agate mortar. Then, the powder of each compound was deposited in the hollow of very thin glass sample holder which has nearly zero background plate. The X-ray diffraction data were collected by overnight scans in the $2 \theta$ range of $7-105^{\circ}$ with steps of $0.02^{\circ}$ and $0.5 \mathrm{~s}$ per step using a Bruker AXS D8 da Vinci diffractometer, equipped with Ni-filtered CuK $\alpha$ radiation $(\lambda=1.5418 \AA$ ) and a Lynxeye linear position-sensitive detector. The following optics were set up: primary beam Soller slits $\left(2.94^{\circ}\right)$, fixed divergence slit $\left(0.3^{\circ}\right)$ and receiving slit $(8 \mathrm{~mm})$. The generator was set at $40 \mathrm{kV}$ and $40 \mathrm{~mA}$. Approximate unit cell parameters were determined using 20 first standard peaks, followed by indexing through the singlevalue decomposition approach [23] implemented in TOPAS [24]. In all cases, space group $P 2_{1} / n$ was chosen after careful analysis of systematic absences and the cell parameters were refined using 7-55 $2 \theta$ range by Pawley method [25]. The successful structure solution processes were performed by the simulated annealing technique [26] also implemented in TOPAS. No higher symmetric system was suggested by PLATON [27]. The structure solution of each complex was carried out using four full rigid bodies, being one for neutral phen ligand and three for the anionic hcin ligands, all of them with free location and orientation and three refinable torsion angles $\left(\tau_{1}, \tau_{2}, \tau_{3}\right.$, ) for hcin anions, see Chart 1 . Rigid bodies of ligands were defined by the Z-matrix formalism using standard distances and angle bonds already reported in literature [28,29]. $\mathrm{Ln}(\mathrm{III})$ ions ( $\mathrm{Ln}=\mathrm{Eu}, \mathrm{Gd}$ and $\mathrm{Tb})$ were also left free in translation. It is worth noting that in the structure solution step there are 36 parameters to be determined and it is the beyond of powder $\mathrm{X}$-ray diffraction state-of-art. However, using some soft restrains as Eu-O below than $2.8 \AA$, feasible and robust crystallographic models were afforded in this step after some hours of computation procedures.

In all cases, the final crystal model refinements afforded in former step were carried out by the well-known Rietveld method [30] where the rigid body description introduced at the solution stage was maintained, but without any restrains. The background was modeled by a Chebyshev polynomial function. Isotropic thermal parameters set up as $3.3(0.1) \AA^{2}$ for $1,0.95(0.1) \AA^{2}$ for 2 and 2.7 (0.1) $\AA^{2}$ for 3 were assigned to all atoms. A summary of crystal data and data collection parameters are presented in Table 1 . The final Rietveld refinement plots are supplied as Supplementary Materials S1-S3 for 1, 2 and $\mathbf{3}$ complexes, respectively.

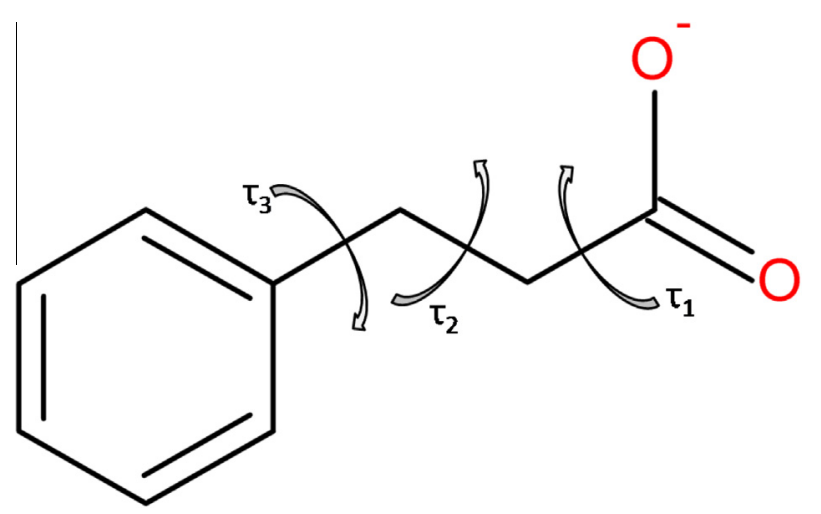

Chart 1. Sketch of hydrocinnamate-hcin ion. The $\tau_{1}$ to $\tau_{3}$ illustrate the torsion angles defining the conformation of the organic moiety in describing the full conformation of the whole ligand. 
Table 1

Main crystallographic data of $\left[\operatorname{Ln}_{2}(\text { hcin })_{6}(\text { phen })_{2}\right]$ complexes.

\begin{tabular}{|c|c|c|c|}
\hline & $\mathbf{1}\left[\mathrm{Eu}_{2}(\text { hcin })_{6}(\text { phen })_{2}\right]$ & $\mathbf{2}\left[\mathrm{Gd}_{2}(\text { hcin })_{6}(\text { phen })_{2}\right]$ & $3\left[\mathrm{~Tb}_{2}(\text { hcin })_{6}(\text { phen })_{2}\right]$ \\
\hline Empirical formula & $\mathrm{Eu}_{2}\left(\mathrm{C}_{9} \mathrm{H}_{9} \mathrm{O}_{2}\right)_{6}\left(\mathrm{C}_{12} \mathrm{H}_{8} \mathrm{~N}_{2}\right)_{2}$ & $\mathrm{Gd}_{2}\left(\mathrm{C}_{9} \mathrm{H}_{9} \mathrm{O}_{2}\right)_{6}\left(\mathrm{C}_{12} \mathrm{H}_{8} \mathrm{~N}_{2}\right)_{2}$ & $\mathrm{~Tb}_{2}\left(\mathrm{C}_{9} \mathrm{H}_{9} \mathrm{O}_{2}\right)_{6}\left(\mathrm{C}_{12} \mathrm{H}_{8} \mathrm{~N}_{2}\right)_{2}$ \\
\hline Formula weight & 1559.34 & 1569.92 & 1573.26 \\
\hline$T(\mathrm{~K})$ & 295 & 295 & 295 \\
\hline$\lambda(\mathrm{Cu} \mathrm{K} \alpha)(\AA)$ & 1.5418 & 1.5418 & 1.5418 \\
\hline Crystal system & monoclinic & monoclinic & monoclinic \\
\hline Space group & $P 2_{1} / n$ & $P 2_{1} / n$ & $P 2_{1} / n$ \\
\hline$a(\AA)$ & $13.551(3)$ & $13.530(4)$ & $13.507(4)$ \\
\hline$b(\AA)$ & $22.355(4)$ & $22.340(6)$ & $22.346(6)$ \\
\hline$c(\AA)$ & $12.333(3)$ & $12.316(4)$ & $12.301(4)$ \\
\hline$\beta\left({ }^{\circ}\right)$ & $66.14(2)$ & $66.12(2)$ & $66.09(2)$ \\
\hline$V\left(\AA^{3}\right)$ & $3416.9(1)$ & $3304.1(2)$ & $3394.0(2)$ \\
\hline$Z$ & 4 & 4 & 4 \\
\hline$D_{\text {calc }}\left(\mathrm{g} / \mathrm{cm}^{3}\right)$ & 1.516 & 1.532 & 1.539 \\
\hline$\mu\left(\mathrm{mm}^{-1}\right)$ & 12.27 & 12.98 & 10.27 \\
\hline$F(000)$ & 1632 & 1640 & 1644 \\
\hline Number of parameters & 59 & 54 & 53 \\
\hline$R_{\text {Bragg }}, R_{\mathrm{wp}}$ & $0.022 / 0.033$ & $0.024 / 0.030$ & $0.019 / 0.032$ \\
\hline
\end{tabular}

\subsection{Synthesis of $\left[\operatorname{Ln}_{2}(\text { hcin })_{6}(\text { phen })_{2}\right]$}

An ethanolic solution $(10 \mathrm{~mL})$ containing $24 \mathrm{mg}(0.13 \mathrm{mmol})$ of 1,10-phenanthroline was slowly added to an aqueous suspension $(30 \mathrm{~mL})$ containing $60 \mathrm{mg}$ of Hhcin $(0.40 \mathrm{mmol}), 50 \mathrm{mg}$ of $\mathrm{LnCl}_{3^{-}}$ $.6 \mathrm{H}_{2} \mathrm{O}(0.13 \mathrm{mmol})$ and $\mathrm{NaOH}$ aqueous solution $(0.40 \mathrm{~mL}$, $\left.1 \mathrm{~mol} \mathrm{~L}^{-1}\right)$. The mixture was stirred at room temperature for $24 \mathrm{~h}$ and a white solid was formed. The solid was filtered, washed three times with ethanol and acetone and dried in air.

$\left.\left[\mathrm{Eu}_{2} \text { (hcin) }\right)_{6}(\text { phen })_{2}\right]$ (1): Yield: 73\%. Anal. Calc. for $\mathrm{C}_{78} \mathrm{H}_{70} \mathrm{O}_{12} \mathrm{~N}_{4^{-}}$ $\mathrm{Eu}_{2}$ : C, 60.08; H, 4.52; N, 3.59. Found: C. 59.8; H, 4.51; N, 3.63\%.

$\left[\mathrm{Gd}_{2}(\text { hcin })_{6}(\text { phen })_{2}\right]$ (2): Yield: $74 \%$. Anal. Calc. for $\mathrm{C}_{78} \mathrm{H}_{70} \mathrm{O}_{12} \mathrm{~N}_{4}-$ $\mathrm{Gd}_{2}$ : C, 59.6; H, 4.49; N, 3.57. Found: C. 59.4; H, 4.49; N, 3.64\%.

$\left.\left[\mathrm{Tb}_{2} \text { (hcin) }\right)_{6}(\text { phen })_{2}\right](3)$ : Yield of $77 \%$. Anal. Calc. for $\mathrm{C}_{78} \mathrm{H}_{70} \mathrm{O}_{12} \mathrm{~N}_{4}$ $\mathrm{Tb}_{2}$ : C, 59.5; H, 4.48; N, 3.56\%. Found: C, 60.2; H, 4.47; N, 3.59\%.

All the compounds are stable in air and exhibited intense luminescence in the primary colors: red (for the compound 1) and green (for the compound 3), when exposed to UV light.

Our research group has some experience on solvothermal synthesis and crystal structures, and recently binuclear hydrocinnamates of $\mathrm{Eu}(\mathrm{III}), \mathrm{Gd}(\mathrm{III})$ and $\mathrm{Tb}(\mathrm{III})$ of general formula $\left[\mathrm{Ln}_{2}(\mathrm{hcin})_{6}(\mathrm{bpy})_{2}\right]$, similar to those studied here, were reported [20]. In this sense, several efforts have been made, including solvothermal synthesis, to obtain single crystals for structural determination through single crystal X-ray diffraction analysis. Fortunately, the obtained solids were crystalline powders and we also have same expertise in solving crystal structures using powder X-ray diffraction (PXRD) data [31-33]. Therefore, in absence of single crystals, the crystallographic models of present lanthanides complexes were provided by PXRD studies and once again, it has been shown that this method can supply relevant and otherwise inaccessible structural information that can be obtained from single crystal analyses [34].

\section{Results and discussion}

All the new complexes described here were confirmed by satisfactory elemental analysis, vibrational spectroscopy (infrared and Raman), CP/MAS ${ }^{13} \mathrm{C}$ NMR, thermal analysis (TG/DTA), X-ray diffraction and photoluminescence study.

From the reaction between $\mathrm{LnCl}_{3} \cdot 6 \mathrm{H}_{2} \mathrm{O}(\mathrm{Ln}=\mathrm{Eu}, \mathrm{Gd}$ and $\mathrm{Tb})$, hydrocinnamic acid (Hhcin) and 1,10-phenanthroline (phen) in 1:4:1 molar quantities, using the conventional agitation method, compounds of general formula $\left.\left[\operatorname{Ln}_{2}(\text { hcin })_{6} \text { (phen) }\right)_{2}\right]$ were obtained. Elemental analysis data of $\mathrm{C}, \mathrm{H}$ and $\mathrm{N}$ indicates the $(1: 3: 1) /(\mathrm{Ln}$
(III):hcin:phen) stoichiometric proportion that is not the same used in the synthetic procedure.

\subsection{Crystal Structures of $\left[\operatorname{Ln}_{2}(\text { hcin })_{6}(\text { phen })_{2}\right]$}

Powder X-ray diffraction analysis reveals that the three lanthanides complexes belong to monoclinic system and space group $P 2_{1} / n$. Since the complexes are isostructural (see Figs. S1-S3 in Supplementary Material), the crystal structure of Eu(III) complex was chosen to be described herein as a representative example. The asymmetric unit of Eu(III) complex is shown in Fig. 1(a) and in Fig. 1(b) is possible to see that the crystal structure, in fact, consists of a discrete dimeric neutral molecule, with molecular formula $\left.\left[\text { Eu }_{2}(\text { hcin })_{6} \text { (phen) }\right)_{2}\right]$. It is interesting to observe that the dimeric system of Eu(III) complex has an inversion center of symmetry located between two $\mathrm{Eu}(\mathrm{III})$ ions indicating that the $\mathrm{Eu}(\mathrm{III})$ ions are both equivalent in the coordination environment. Eu(III) ions are surrounded by seven oxygen atoms from hydrocinnamate ligands and two nitrogen atoms from phenanthroline ligand completing the coordination number nine. The coordination geometry of $\mathrm{Eu}(\mathrm{III})$ is well described as a distorted tricapped trigonal prism (Fig. 1c). The main lengths bonds found in Ln(III) complexes are listed in Table 2.

The carboxylate groups from three crystallographically independent hcin ligands present three different coordination modes as can see in Chart 2. Carboxylate oxygen atoms can act as bidentate chelating, Chart 2(a), and, one of the oxygen atoms $\mathrm{O}$ (or $\mathrm{O} i$ ) is coordinated to another $\operatorname{Ln}(\mathrm{III})$ ion forming a monoatomic bridge or $\mu$-oxo bridge. The carboxylate group can also connect a pair of Eu (III) ions in a syn,syn- $\eta^{1}: \eta^{1}: \mu_{2}$ bidentate bridging fashion, as depicted in Chart 2(b), In coordination mode (c), hcin acts as simple bidentate chelating ligand toward one Eu(III) center with two oxygen atoms from carboxylate group.

Besides the Ln-N and Ln-O lengths, an important value is the distance of $\mathrm{Ln}$... Ln ions. For 1, Eu(III) . . Eu(III) ${ }^{i}$ distance is $4.063 \AA$ and it is slightly larger than in 2 with $\mathrm{Gd}(\mathrm{III}) \ldots \mathrm{Gd}(\mathrm{III})^{i}$ distance of $4.032 \AA$. As expected the $\mathrm{Tb}(\mathrm{III}) \cdots \mathrm{Tb}(\mathrm{III})^{i}$ distance, about $3.992 \AA$, is slightly shorter than in $\mathbf{1}$ and $\mathbf{2}$ since their ionic radii are $0.95 \AA \mathrm{Eu}$ (III) versus $0.94 \AA \AA \mathrm{Gd}$ (III) vs $0.92 \AA \mathrm{Tb}$ (III). Based on the literature [20], Ln-N and Ln-O bond lengths are about 2.6 and 2.4 $\AA$, respectively, and $\mathrm{Ln}-\mathrm{N}$ and $\mathrm{Ln}-\mathrm{O}$ distances in compounds 1-3 vary from 2.59 to 2.75 and from 2.38 to $2.79 \AA$ A (see Table 2).

As discussed previously [20], lanthanide complexes of monoacids can form coordination polymers with bridging carboxylate groups including cinnamate [36], nitrobenzoate [37], 2,3-dimethoxybenzoates [38] and 2-thiopheneacetate [39]. On 

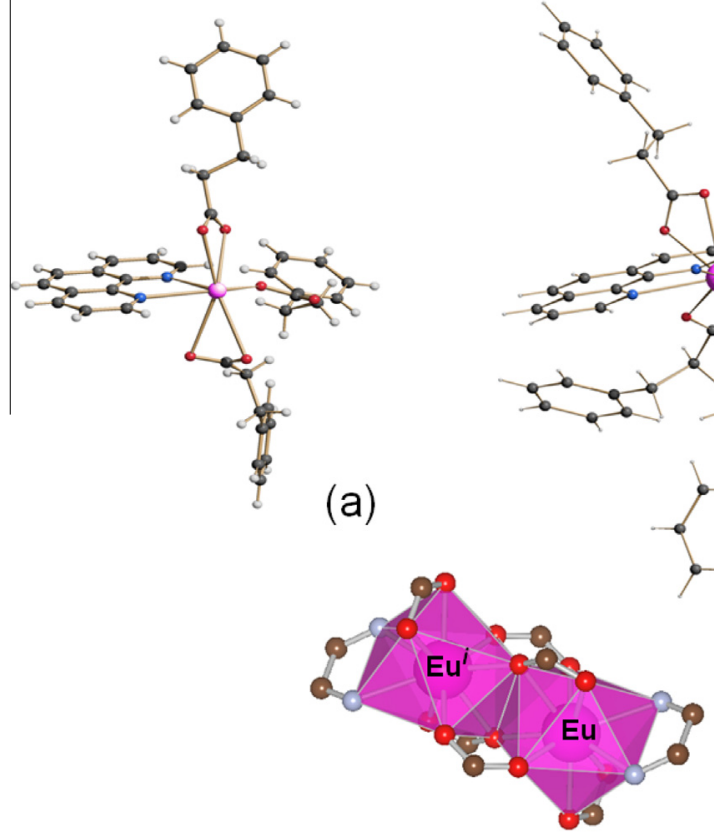

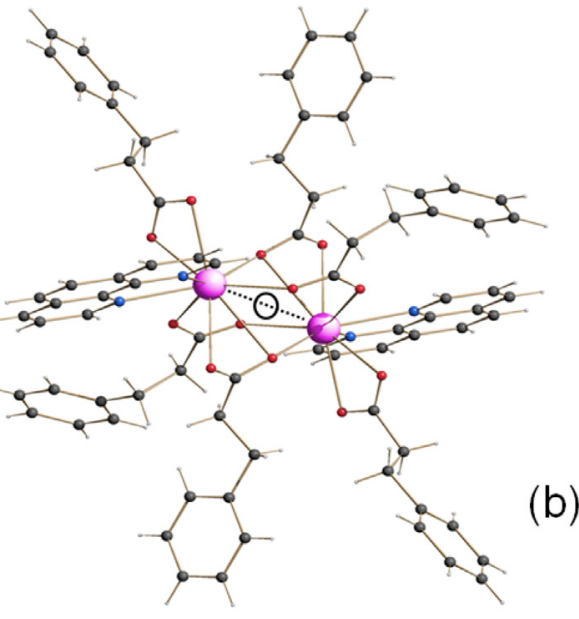

(c)

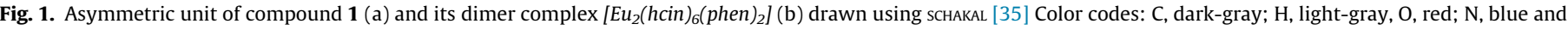

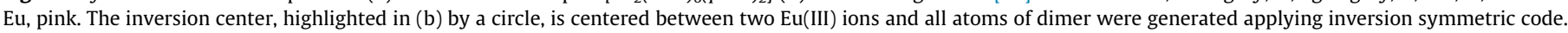

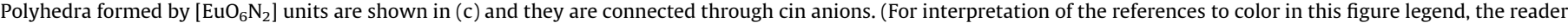
is referred to the web version of this article.)

Table 2

Selected values of bond distances of the $\operatorname{Ln}(\mathrm{III})$ complexes 1, 2 and $\mathbf{3}$.

\begin{tabular}{|c|c|c|c|c|c|}
\hline \multirow[t]{2}{*}{ Complex } & \multirow[t]{2}{*}{$\operatorname{Ln} \cdots \operatorname{Ln}^{\mathrm{i}}$} & \multirow[t]{2}{*}{ Ln-N } & \multicolumn{3}{|c|}{$\begin{array}{l}\text { Lengths }(\AA) \\
\text { Ln-O and } \text { Ln }^{\mathrm{i}}-\mathrm{O}\end{array}$} \\
\hline & & & Mode (a) & Mode (b) & Mode (c) \\
\hline 1 & 4.063 & $\begin{array}{l}2.593(2) \\
2.747(1)\end{array}$ & $\begin{array}{l}2.776(1) \\
2.497(1) \\
2.492(1)^{\mathrm{i}}\end{array}$ & $\begin{array}{l}2.385(2)^{\mathrm{i}} \\
2.499(3)\end{array}$ & $\begin{array}{l}2.515(3) \\
2.480(4)\end{array}$ \\
\hline 2 & 4.032 & $\begin{array}{l}2.688(1) \\
2.609(1)\end{array}$ & $\begin{array}{l}2.708(2) \\
2.555(1) \\
2.478(1)^{\mathrm{i}}\end{array}$ & $\begin{array}{l}2.541(1)^{\mathrm{i}} \\
2.459(1)\end{array}$ & $\begin{array}{l}2.499(1) \\
2.511(2)\end{array}$ \\
\hline 3 & 3.992 & $\begin{array}{l}2.621(7) \\
2.587(8)\end{array}$ & $\begin{array}{l}2.696(1) \\
2.583(1) \\
2.542(1)^{\mathrm{i}}\end{array}$ & $\begin{array}{l}2.588(8) \\
2.543(1)\end{array}$ & $\begin{array}{l}2.487(1) \\
2.488(1)\end{array}$ \\
\hline
\end{tabular}

Symmetry code $i=2-x, 1-y, 1-z$.
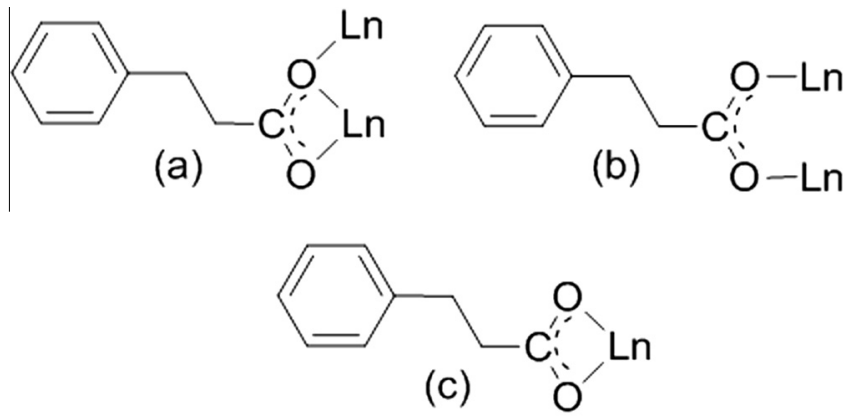

Chart 2. Three possible coordination modes of hydrocinammate ion.

the other hand, dimeric complexes can be achieved when carboxylate ligands along with 2,2'-bipyridine (bpy) or 1,10phenanthroline (phen) are used as exemplified by $\left\{\left[\mathrm{Eu}_{2}(2-\mathrm{BrBA})_{6}\right.\right.$ (bpy $\left.\left.)_{2}\right]_{2} \cdot \mathrm{CH}_{3} \mathrm{CH}_{3} \mathrm{OH} \cdot \mathrm{H}_{2} \mathrm{O}\right\}[54] \quad(2 \mathrm{BrBA}=2$-bromobenzoate) and $\left.\left[\mathrm{Eu}_{2}(3,4-\mathrm{DMBA})_{6} \text { (phen) }\right)_{2}\right][55]$ (3,4-DMBA = 3,4-dimethylbenzoate). Results on the synthesis and crystal structures of complexes with hydrocinnamate anion are unusual $[25,26]$. However, our group has reported the first crystal structures of lanthanide hydrocinnamates $[19,20]$, and to the best of our knowledge, these are still the first structures these compounds. A supramolecular onedimensional (1D) array along $c$ axis has been built by weak nonclassical hydrogen bonds $(\mathrm{CH} \cdots \mathrm{O})$ between the oxygen atom from carboxylate group and aromatic ring $\mathrm{CH}$ groups from the phen ligands $\mathrm{d}(\mathrm{C} 65 \ldots \mathrm{O} 21)=3.364 \AA$ as well $\mathrm{CH}$ from cin- $\mathrm{d}(\mathrm{C} 34 \ldots \mathrm{O} 22)$ $=3.828 \AA$ as shown in Fig. 2 . Other hydrogen bonds between C12-011 are responsible for the formation of a supramolecular network along $a$ and $b$ axes, and together with hydrogen bonds on c axis, a 3D network has been created. Although these interactions are weaker than those of the coordinative bonds, they play an essential role in the construction of multi-dimensional networks in the solid state, as in the present case.

\subsection{Vibrational spectroscopy (infrared and Raman)}

The infrared and Raman spectra of all ligands and complexes were investigated in this work. The similarity of lanthanide complexes IR and Raman spectra indicates that these compounds are isostructural, as have been proved by X-ray diffraction analysis results. The main vibrational modes are summarized in Table 3 , as well as the tentative assignment.

Particular attention was paid to the separation between asymmetric and symmetric stretching frequency values of $\mathrm{COO}^{-}$groups. In this class of compounds, the difference $(\Delta v)$ between $v_{\text {asym }}$ $\left(\mathrm{COO}^{-}\right)$and $v_{\text {sym }}\left(\mathrm{COO}^{-}\right)$in comparison to the corresponding values in ionic species is currently employed to propose the carboxylate group coordination mode [40]. This is an important tool, since lanthanoid carboxylates usually contain a variety of different coordination modes as a result of their large coordination numbers. In the IR spectrum of hcin ${ }^{-}$ligand in ionic form Nahcin, two absorption bands at 1553 and $1418 \mathrm{~cm}^{-1}$ are attributed to $v_{\text {asym }}\left(\mathrm{COO}^{-}\right)$ and $v_{\text {sym }}\left(\mathrm{COO}^{-}\right)$stretching modes, respectively, providing $\Delta v=135 \mathrm{~cm}^{-1}$. The FTIR and Raman spectra of the complexes show a band attributed to $v_{\text {asym }}\left(\mathrm{COO}^{-}\right)$vibrational mode at 


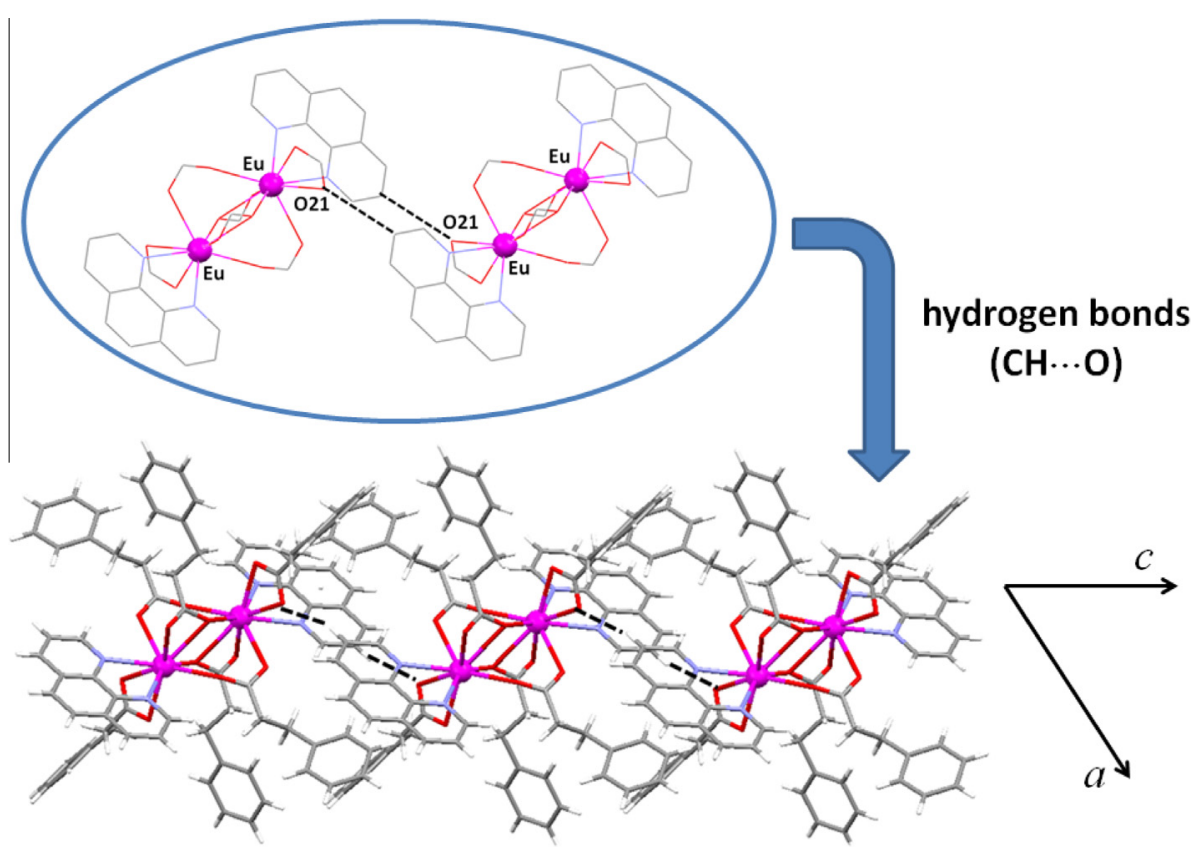

supramolecular 1D array

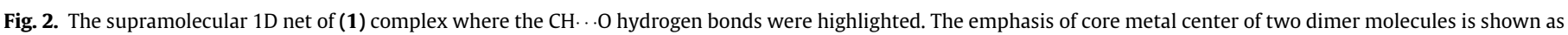
inset.

Table 3

Infrared (IR) and Raman (R) wavenumbers (in $\mathrm{cm}^{-1}$ ) and tentative assignment of the most important bands for ligands (Nahcin and 1,10-phen) and 1-3 complexes.

\begin{tabular}{|c|c|c|c|c|c|c|c|c|c|c|}
\hline \multicolumn{2}{|l|}{ Nahcin } & \multicolumn{2}{|l|}{ 1,10-phen } & \multicolumn{2}{|l|}{ (1) } & \multicolumn{2}{|l|}{ (2) } & \multicolumn{2}{|l|}{ (3) } & \multirow[t]{2}{*}{ Assignment } \\
\hline IR & $\mathrm{R}$ & IR & $\mathrm{R}$ & IR & $\mathrm{R}$ & IR & $\mathrm{R}$ & IR & $\mathrm{R}$ & \\
\hline- & - & - & - & $475(w)$ & $473(w)$ & $475(w)$ & $473(w)$ & $475(w)$ & $473(w)$ & $v(\mathrm{Ln}-\mathrm{N})$ \\
\hline- & - & - & - & $545(w)$ & $548(w)$ & $545(w)$ & $548(w)$ & $545(w)$ & $548(w)$ & $v(\operatorname{Ln}-\mathrm{O})$ \\
\hline $825(w)$ & $819(w)$ & $856(\mathrm{~s})$ & $857(w)$ & $845(\mathrm{~m})$ & - & $845(\mathrm{~m})$ & - & $845(\mathrm{~m})$ & - & $\delta_{\text {o.p }}(\mathrm{CH})$ \\
\hline- & - & $1598(\mathrm{~m})$ & $1598(\mathrm{~m})$ & 1606 (vs) & $1606(\mathrm{~m})$ & 1606 (vs) & $1606(\mathrm{~m})$ & 1606 (vs) & $1606(\mathrm{~m})$ & $v(\mathrm{C}=\mathrm{N})$ \\
\hline 1418 (vs) & 1416 (vs) & - & - & 1421 (vs) & 1421 (vs) & 1421 (vs) & 1421 (vs) & 1421 (vs) & 1421 (vs) & $v_{\mathrm{sym}}\left(\mathrm{COO}^{-}\right)$ \\
\hline $1553(\mathrm{~s})$ & $1552(\mathrm{~s})$ & - & - & $1521(w)$ & $1521(w)$ & $1521(w)$ & $1521(w)$ & $1521(w)$ & $1521(\mathrm{w})$ & $v_{\text {asym }}\left(\mathrm{COO}^{-}\right)$ \\
\hline $2922(s)$ & 2917 (s) & $2986(w)$ & $2992(w)$ & $2919(w)$ & 2917 (s) & $2919(w)$ & 2917 (s) & $2919(w)$ & $2917(\mathrm{~s})$ & $v(\mathrm{CH})_{\text {aliph. }}$ \\
\hline $3032(\mathrm{~m})$ & $3030(\mathrm{~m})$ & $3064(w)$ & $3058(\mathrm{~m})$ & $3021(w)$ & $3030(s)$ & $3021(w)$ & $3030(s)$ & $3021(w)$ & $3030(s)$ & $v(\mathrm{CH})_{\text {atom. }}$ \\
\hline
\end{tabular}

Abbreviations: vs, very strong; s, strong; m, medium; w, weak; o.p, out-of-plane; asym, asymmetric; sym, symmetric; aliph, aliphatic; arom, aromatic.

$1521 \mathrm{~cm}^{-1}$, while the $v_{\text {sym }}\left(\mathrm{COO}^{-}\right)$appears in $1421 \mathrm{~cm}^{-1}$. The calculated value of $\Delta v=100 \mathrm{~cm}^{-1}$ is close to the value expected for a chelate coordination mode of the carboxylate moiety, in agreement with by X-ray diffraction analysis results. Additionally, the absorption at $1598 \mathrm{~cm}^{-1}$ of the $\mathrm{C}=\mathrm{N}$ stretching frequencies in the free phen spectrum are shifted to higher wavenumbers $\left(1606 \mathrm{~cm}^{-1}\right)$ in $\left.\left[\operatorname{Ln}_{2}(\text { hcin })_{6} \text { (phen }\right)_{2}\right]$ complexes. This indicates the nitrogen ligand coordination to the lanthanide centers through the pyridine nitrogen atom, as observed for previous structurally characterized compounds containing pyridil rings [20].

\subsection{Thermal analysis}

Thermal behavior, particular stability and volatility, is important for practical applications in luminescent materials. The thermal analysis (TGA/DTA) was carried out using 1-3 polycrystalline samples in the temperature range of $19-800{ }^{\circ} \mathrm{C}$ under argon atmosphere. Because complexes 1-3 are isomorphous, their TGA curves are similar (Fig. S4 in Supplementary Material). Therefore only complex 3 will be discussed in detail as a representative compound for this group. As can be seen in TG/DTA curves (Fig. 3), the compound is stable up to $238^{\circ} \mathrm{C}$, indicating the absence of water

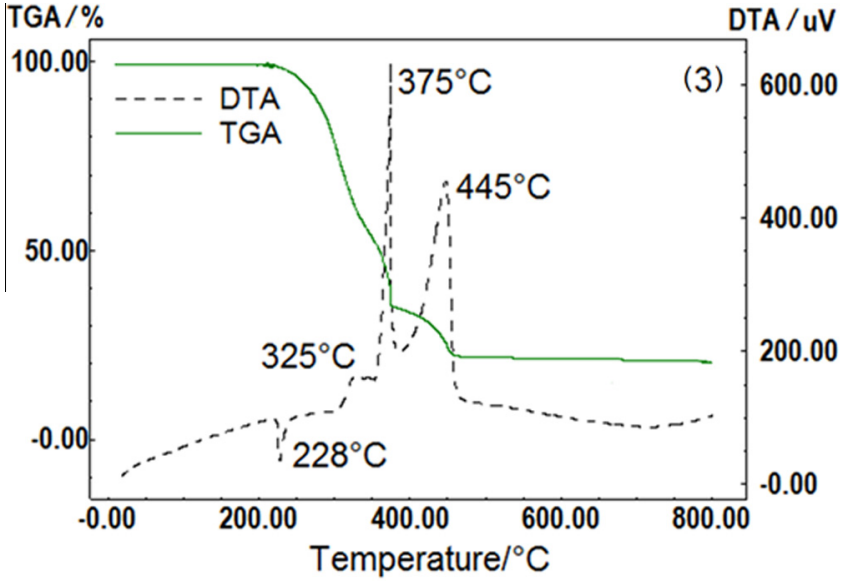

Fig. 3. TGA (-) and DTA (----) traces in Ar atmosphere for compound 3.

molecules in its structure. The first endothermic event centered at $228^{\circ} \mathrm{C}$ is probably related to the melting point for the complex. After the fusion of complex, three consecutive exothermic events 
occur (centered at: 325,375 and $445{ }^{\circ} \mathrm{C}$ ) which are related to consecutive thermal decomposition steps. The first one, between 238 and $313{ }^{\circ} \mathrm{C}$, corresponds to the release of two phen ligands (Obsd: $22.0 \%$, Calcd: $22.8 \%$ ). The second and third mass losses, observed from 313 to $459^{\circ} \mathrm{C}$, are consistent with the decomposition of approximately six hydrocinnamate ligands (Obsd: $55.1 \%$, Calcd: $56.8 \%$ ). At $800{ }^{\circ} \mathrm{C}$, the residual percentage weight is consistent with half a mol of $\mathrm{Tb}_{4} \mathrm{O}_{7}$ (Obsd. 22.9\%, Calcd: 23.7\%).

\subsection{CP/MAS ${ }^{13} \mathrm{C}$ NMR spectra analysis}

The CP/MAS ${ }^{13} \mathrm{C}$ NMR spectra of complex 1 and Hhcin and phen ligands are shown in Fig. S5 in Supplementary Material. Through the analysis of complex 1 spectrum, signals between d 24.4 and $34.0 \mathrm{ppm}$, attributed to methylene carbons of hcin ligand were observed. The presence of four signals in this region indicates different hcin ligands in the complex 1 structure, which is in accordance with vibrational spectroscopy (infrared and Raman) and PXRD analysis. The signals between $\delta 91.8$ and $156.3 \mathrm{ppm}$ were attributed to aromatic carbons from phen and hcin structure. The spectrum of complex $\mathbf{1}$, in comparison with the ligands spectra shows a shielding of some aromatic carbons, more precisely, the peaks between $\delta 90.0$ and $105.0 \mathrm{ppm}$. Probably, this is due to the HALA Effect (Heavy Atom on the Light Atom Effect), where a heavy atom, Eu(III) in this case, induces a shielding (or deshielding) on close light nuclei [41]. Finally, the signal around $\delta 210.0 \mathrm{ppm}$ refers to the carboxylate carbon which appears deshielding when compared with the free Hhcin ligand spectrum, because of the decreasing on electron density, as a result of the complex formation.

Unfortunately, it was not possible to obtain CP/MAS ${ }^{13} \mathrm{C}$ NMR spectra of $\mathrm{Gd}(\mathrm{III})$ and $\mathrm{Tb}(\mathrm{III})$ complexes, probably due to their large paramagnetic effect [42], since the cross-polarization technique is susceptible to signal loss in the presence of paramagnetic species $[42,43]$. In addition, lanthanides may influence the relaxation time, also inducing the NMR signal loss.

\subsection{Photoluminescence study}

\subsubsection{Phosphorescence of the Gd(III) complex}

The corresponding gadolinium complex was used as a model complex for the determination of the first triplet state energies of the organic ligands ( $T_{1} \rightarrow S_{0}$ transitions) owing to their high phosphorescence/fluorescence ratio compared to those of other $\operatorname{Ln}(\mathrm{III})$ complexes and because of their structural similarity with Eu(III) and $\mathrm{Tb}(\mathrm{III})$ complexes. The $\mathrm{Gd}(\mathrm{III})$ complexes are proper for this determination due to the high energy gap (approximately $\left.32,000 \mathrm{~cm}^{-1}\right)$ between the ground $\left({ }^{8} \mathrm{~S}_{7 / 2}\right)$ and excited $\left({ }^{6} \mathrm{P}_{7 / 2}\right)$ levels within the $4 f^{7}$ configuration which avoids the energy transfer from the ligand triplet to the metal excited levels. In this context, the larger probability of ligand phosphorescence is due to a combination of both paramagnetic [44] and heavy-atom effects [45]. The steady-state phosphorescence spectrum of gadolinium complex recorded at liquid nitrogen temperature from 385 to $480 \mathrm{~nm}$ with excitation at $330 \mathrm{~nm}$ is shown inset in Fig. 4. This spectrum is characterized by one very low intensity broad band in the spectral range of $380-450 \mathrm{~nm}$ and the strongest band which are assigned to $S_{0} \rightarrow S_{1}$ (fluorescence band) and to $T_{1} \rightarrow S_{0}$ (phosphorescence band) transitions of the ligands, respectively. This behavior has been observed for other lanthanide carboxylate complexes reported in the literature [20]. The phosphorescence band extends to longer wavelengths values presenting a high intensity due to an efficient energy transfer process to $\mathrm{Eu}(\mathrm{III})$ ion. This fact is caused by natural percentage of europium contained in gadolinium oxide used to synthesize the compound $\left.\left[G_{2}(\text { hcin })_{6} \text { (phen }\right)_{2}\right]$. In order to determine unequivocally the energy due to the $0-0$ phonon transition for the $\mathrm{Gd}(\mathrm{III})$ complex, the time-resolved spectrum (Fig. 4)

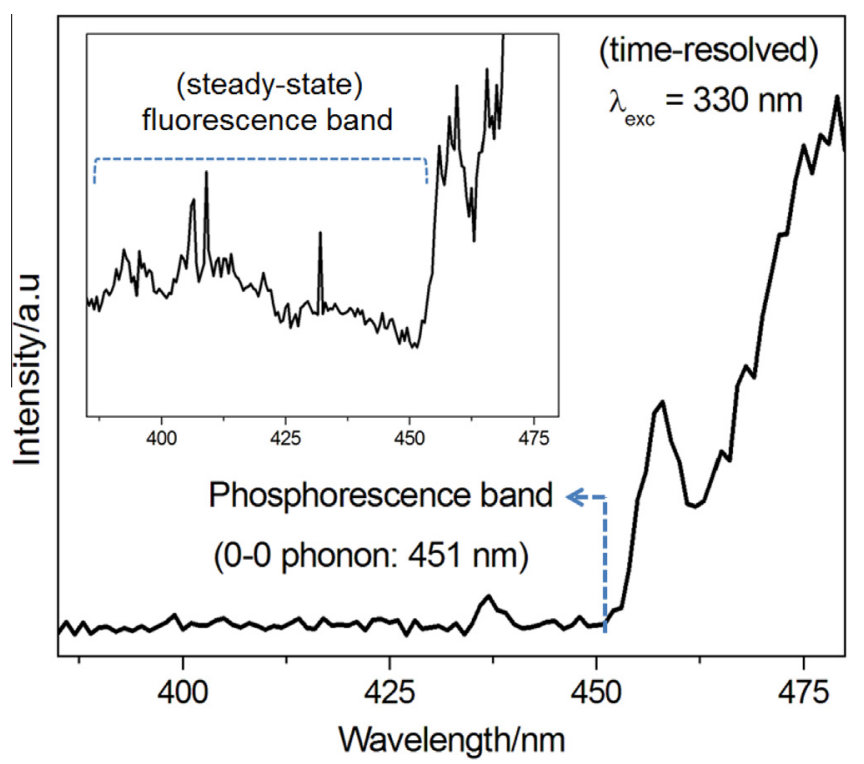

Fig. 4. Time-resolved luminescence spectrum of $\mathrm{Gd}(\mathrm{III})$ complex in solid state at $77 \mathrm{~K}$, upon excitation at $330 \mathrm{~nm}$. (Inset: Phosphorescence data using the steadystate technique).

was recorded at liquid nitrogen temperature with the excitation and emission monitored at 330 and $495 \mathrm{~nm}$, respectively, using $1.0 \mathrm{~ms}$ delay. In this case, the fluorescence bands decrease very fast as the flash delay is increased and only the phosphorescence spectrum from the ligands is displayed. As can be seen, this spectrum presents only a broad band that may be attributed to the triplet to singlet transition. The lowest ligand $\mathrm{T}_{1}$ state energy was determined as the shortest wavelength phosphorescence band (0-0 phonon transition) for the complex $\left.\left[G_{2}(\text { hcin })_{6} \text { (phen) }\right)_{2}\right]$ and appears at approximately $451 \mathrm{~nm}\left(22,172 \mathrm{~cm}^{-1}\right)$. So, the high emission intensity observed for the $\left[\mathrm{Eu}_{2}(\text { hcin })_{6}(\text { phen })_{2}\right]$ and $\left[\mathrm{Tb}_{2}(\text { hcin })_{6}\right.$ (phen $)_{2}$ ] complexes can be explained by an efficient antenna effect with this triplet state having higher energy than the main emitting states of $\mathrm{Eu}(\mathrm{III})\left({ }^{5} \mathrm{D}_{0}\right)$ and $\mathrm{Tb}(\mathrm{III})\left({ }^{5} \mathrm{D}_{4}\right)$, indicating the possibility of intramolecular energy transfer for these ions.

\subsubsection{Photoluminescence of $\left[\operatorname{Ln}_{2}(\text { hcin })_{6}(\text { phen })_{2}\right](\operatorname{Ln}=E u(I I I)(\mathbf{1})$ and $\mathrm{Tb}(\mathrm{III})(3)$ )}

Fig. 5a shows the excitation spectrum of the $\left[\mathrm{Eu}_{2}(\text { hcin })_{6}(\text { phen })_{2}\right]$ 1 recorded at $303 \mathrm{~K}$ in the $250-500$ range by monitoring the $\mathrm{Eu}(\mathrm{III})$ emission at $616 \mathrm{~nm}$. This spectrum exhibits a broad band between 250 and $360 \mathrm{~nm}$ which is attributable to the ligand centered $\mathrm{S}_{0} \rightarrow \mathrm{S}_{1}\left(\pi, \pi^{*}\right)$ transition of the aromatic moiety or with a possible charge transfer (LMCT). The absorption bands are originated from the ${ }^{7} \mathrm{~F}_{0}$ ground state to the excited levels ${ }^{5} \mathrm{~L}_{\mathrm{J}}:{ }^{5} \mathrm{G}_{6}(363 \mathrm{~nm}),{ }^{5} \mathrm{H}_{4}$ $(379 \mathrm{~nm}),{ }^{5} \mathrm{~L}_{7}(385 \mathrm{~nm}),{ }^{5} \mathrm{~L}_{6}(394 \mathrm{~nm}),{ }^{5} \mathrm{D}_{3}(415 \mathrm{~nm})$ and ${ }^{5} \mathrm{D}_{2}$ $(464 \mathrm{~nm})$ excited states. The ${ }^{7} \mathrm{~F}_{0} \rightarrow{ }^{5} \mathrm{~L}_{6}$ transition exhibits the highest absorption intensity among the $4 f^{6}$ intraconfigurational transitions of $\mathrm{Eu}(\mathrm{III})$ ion, indicating that this transition is more efficient for the direct excitation in this metal center. However, these transitions are less intense than those attributable to the ligands levels, which proves that luminescence sensitization is more efficient than the direct excitation of the Eu(III) ion absorption levels.

The emission spectrum of Eu(III) complex, showed in Fig. 5b, provides a lot of information about the point symmetry the Eu (III) ion [46]. Complex 1 exhibits several characteristic emission bands ${ }^{5} \mathrm{D}_{0} \rightarrow{ }^{7} \mathrm{~F}_{\mathrm{J}}(\mathrm{J}=0-4)$ upon excitation in the ligand absorption band, at $330 \mathrm{~nm}$. The presence of the ${ }^{5} \mathrm{D}_{0} \rightarrow{ }^{7} \mathrm{~F}_{0}$ transition indicates that $\mathrm{Eu}(\mathrm{III})$ ion may be located at a symmetry site of the type $C_{\mathrm{s}}, C_{\mathrm{n}}$ or $C_{n v}$, as the selection rules for the electric dipole transition 

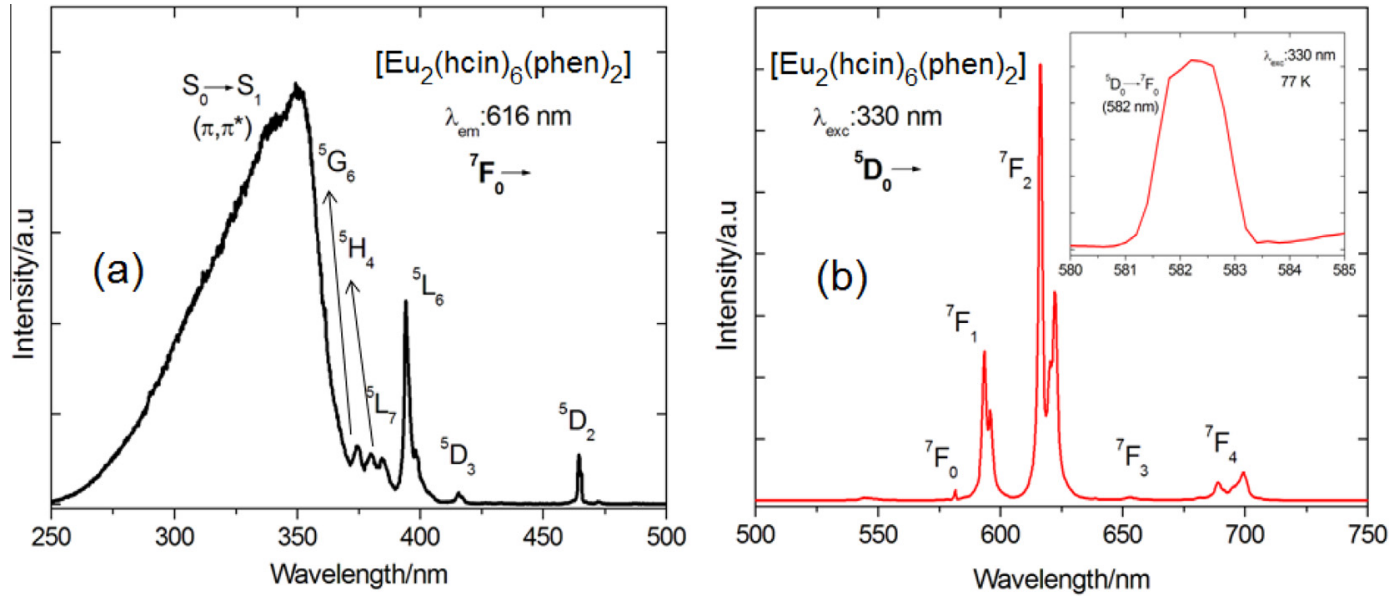

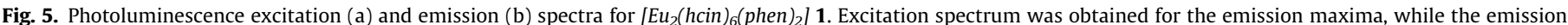
spectrum was monitored on the ligands band, at $330 \mathrm{~nm}$.
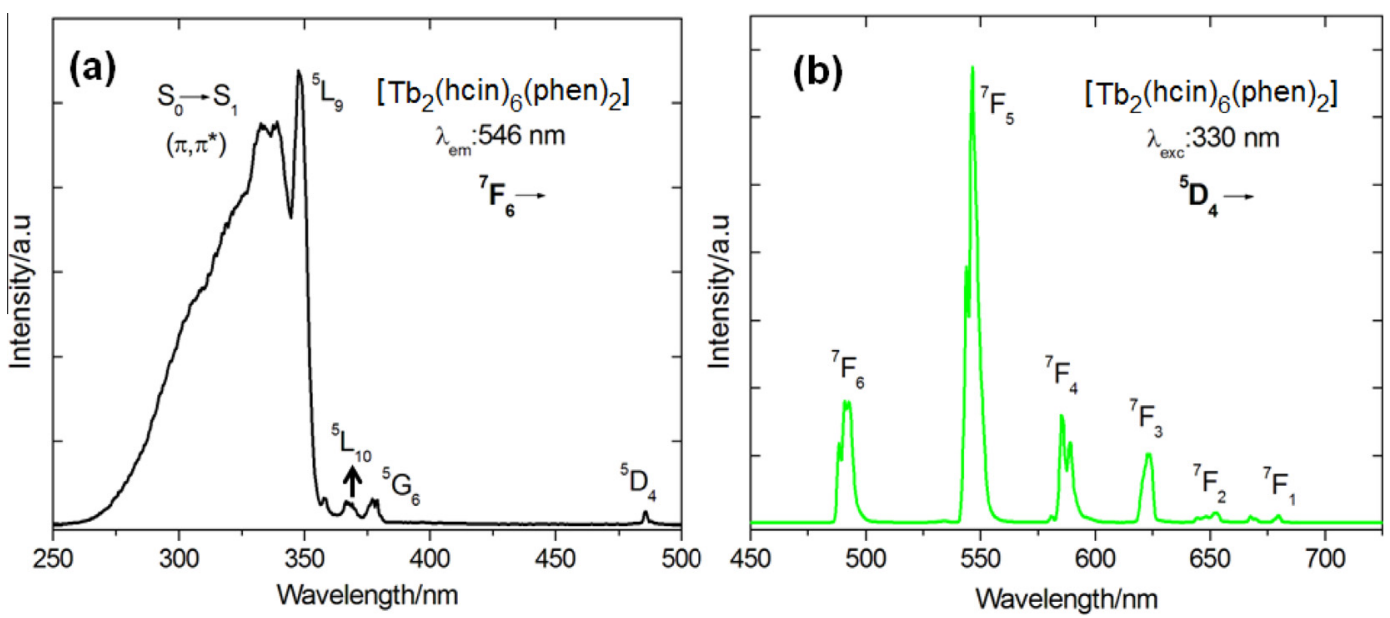

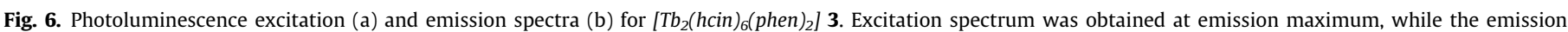
spectrum was obtained in the solid state, upon excitation at $330 \mathrm{~nm}$.

provides. This transition (582 nm) consists of only one peak, which gives a strong indication that the $\mathrm{Eu}(\mathrm{III})$ ions experience the same crystal-field strength and occupy sites of same symmetry. To confirm these results, an emission spectrum in ${ }^{5} \mathrm{D}_{0} \rightarrow{ }^{7} \mathrm{~F}_{0}$ region was obtained at $77 \mathrm{~K}$ (inset in Fig. 7b), and no splitting of this band was observed, corroborating with the crystallographic data. Additionally, a prominent feature that may be observed in this spectrum is the high intensity of ${ }^{5} \mathrm{D}_{0} \rightarrow{ }^{7} \mathrm{~F}_{2}$ transition, which indicates that a highly polarizable chemical environment around the Eu (III) ion of this complex was responsible for the strong brilliant red emission.

Fig. 6a shows the excitation spectrum of the $\left[\mathrm{Tb}_{2}(\text { hcin })_{6}(\text { phen })_{2}\right]$ 3 complex recorded at $303 \mathrm{~K}$ in the 250-500 range, monitoring the emission from the ${ }^{5} \mathrm{D}_{4} \rightarrow{ }^{7} \mathrm{~F}_{5}$ transition at around $546 \mathrm{~nm}$. As shown in Fig. 6a, a broad band was noted between 250 and $345 \mathrm{~nm}$, which was assigned to intraligand transitions. Several Laporte-forbidden $f-f$ transition bands at $355-500 \mathrm{~nm}$ range, corresponding to characteristic transitions of $\mathrm{Tb}$ (III) ion can be noticed. These bands were assigned to ${ }^{7} \mathrm{~F}_{6} \rightarrow{ }^{5} \mathrm{~L}_{9}(353 \mathrm{~nm})$, ${ }^{7} \mathrm{~F}_{6} \rightarrow{ }^{5} \mathrm{~L}_{10}(367 \mathrm{~nm}),{ }^{7} \mathrm{~F}_{6} \rightarrow{ }^{5} \mathrm{G}_{6}(378 \mathrm{~nm})$ and ${ }^{7} \mathrm{~F}_{6} \rightarrow{ }^{5} \mathrm{D}_{4}(485 \mathrm{~nm})$ transitions. Complex $\mathbf{3}$ exhibits several characteristic emission bands upon excitation in the ligand absorption band, at $330 \mathrm{~nm}$ (Fig. 6b). The emission spectrum is composed of the typical $\mathrm{Tb}$ (III) green emission, corresponding to ${ }^{5} \mathrm{D}_{4} \rightarrow{ }^{7} \mathrm{~F}_{6} \quad$ (488 and
$491 \mathrm{~nm}),{ }^{5} \mathrm{D}_{4} \rightarrow{ }^{7} \mathrm{~F}_{5}$ (543 and $\left.546 \mathrm{~nm}\right),{ }^{5} \mathrm{D}_{4} \rightarrow{ }^{7} \mathrm{~F}_{4}$ (583, 585 and $589 \mathrm{~nm}),{ }^{5} \mathrm{D}_{4} \rightarrow{ }^{7} \mathrm{~F}_{3}(623 \mathrm{~nm}),{ }^{5} \mathrm{D}_{4} \rightarrow{ }^{7} \mathrm{~F}_{2}(644,648$ and $652 \mathrm{~nm})$ and ${ }^{5} \mathrm{D}_{4} \rightarrow{ }^{7} \mathrm{~F}_{1}(685 \mathrm{~nm})$. The compound was also excited in the intense transition $\left({ }^{7} \mathrm{~F}_{6} \rightarrow{ }^{5} \mathrm{~L}_{9}\right.$ transition), but no difference in $4 f-4 f$ transitions profile was observed, indicating that the same emission mechanism takes place. These results suggest a high photoluminescence emission of complex 3 when excited directly at the $\mathrm{Tb}$ (III) ion, unlike the complex $\left[\mathrm{Eu}_{2}(\text { hcin })_{6}(\text { phen })_{2}\right]$ (1) where the sensitization through the ligands is more efficient.

One of factors that governs the luminescence efficiency of lanthanide complexes is the energy-level match between the ligand triplet states and $\operatorname{Ln}(\mathrm{III})$ ion ${ }^{5} \mathrm{D}_{\mathrm{J}}$ state. Thus, the back energy-transfer process is one of the major mechanism of luminescence quenching in $\mathrm{Tb}$ (III) complexes. In this context, Latva's empirical rule states [47] show that an efficient ligand-to-metal energy transfer process for $\operatorname{Ln}\left(\right.$ III) needs $\Delta E\left({ }^{3} \pi \pi^{*}-c^{5} D_{J}\right)>2000 \mathrm{~cm}^{-1}$ for $\mathrm{Tb}(\mathrm{III})$. In complex 3 , the energy gap, $\Delta E\left({ }^{3} \pi \pi^{*}-c^{5} \mathrm{D}_{4}\right)$ is lower $\left(1798 \mathrm{~cm}^{-1}\right)$ than the optimal value, however the ligand-to-metal energy transfer process is still effective, despite the back energy transfer between ${ }^{5} \mathrm{D}_{4}$ levels of $\mathrm{Tb}(\mathrm{III})$ ion and ${ }^{3} \pi \pi^{*}$. Marques et al. recently reported the $\left[\mathrm{Tb}_{2}(\mathrm{hcin})_{6}(\text { bpy })_{2}\right]$ [20] complex, in which the energy gap is $2173 \mathrm{~cm}^{-1}$, and thus the back energy-transfer process has no significant importance in this compound. The smallest energy gap in $\left.\left[\mathrm{Tb}_{2}(\text { hcin })_{6} \text { (phen }\right)_{2}\right]$ compound, studied here, can 


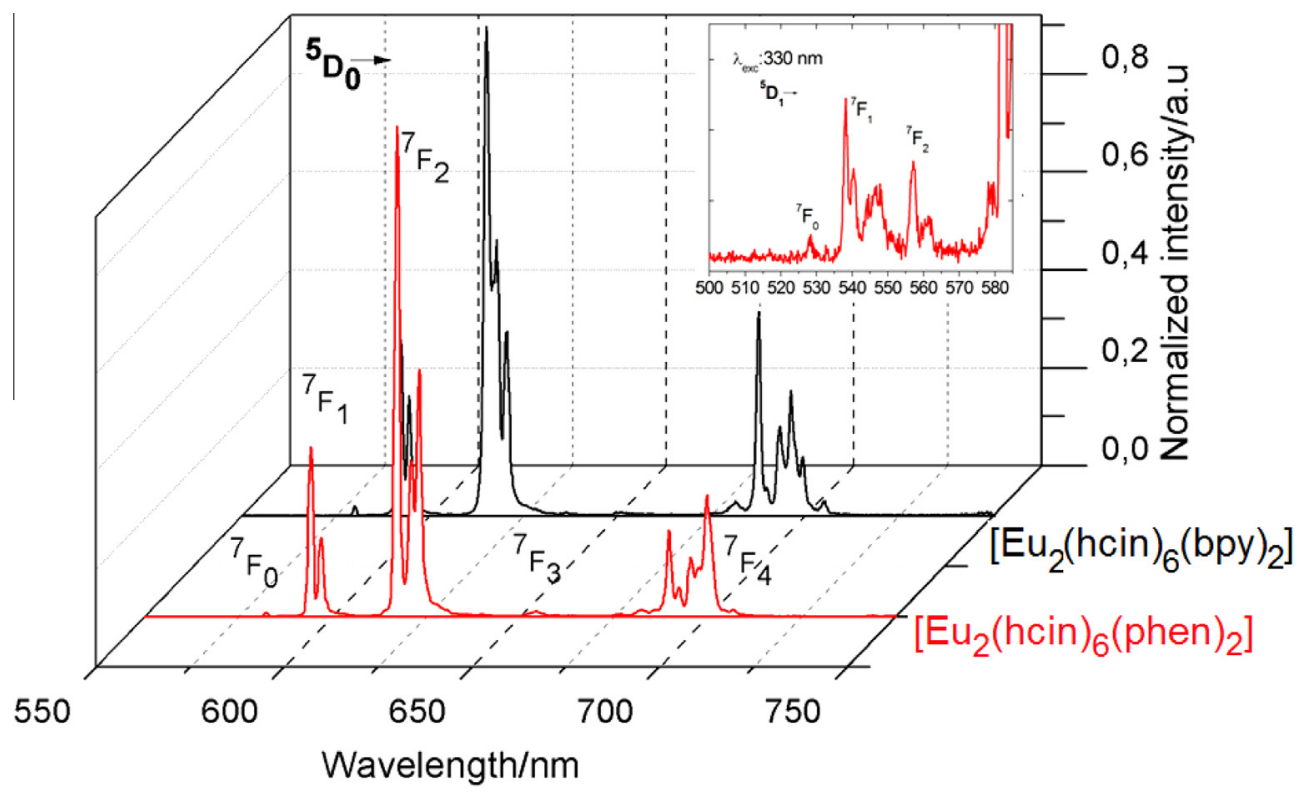

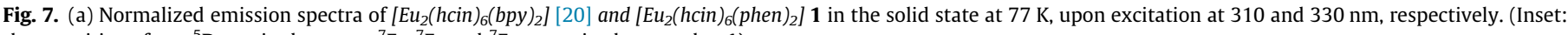
the transitions from ${ }^{5} \mathrm{D}_{1}$ excited state to ${ }^{7} \mathrm{~F}_{0},{ }^{7} \mathrm{~F}_{1}$ and ${ }^{7} \mathrm{~F}_{2}$ states in the complex $\mathbf{1}$ ).

be explained checking triplet states energy: $22,172 \mathrm{~cm}^{-1}$ in $\left[G d_{2}\right.$ (hcin) ${ }_{6}$ (phen) $\left.)_{2}\right]$ and $22,573 \mathrm{~cm}^{-1}$ in $\left.\left[\mathrm{Gd}_{2} \text { (hcin) }{ }_{6} \text { (bpy) }\right)_{2}\right]$ [20]. In order to get further information on the Eu(III) ion chemical environment for the $\left[E u_{2}(\text { hcin })_{6}(\text { phen })_{2}\right] \mathbf{1}$ complex, the experimental $\Omega_{2}$ and $\Omega_{4}$ intensity parameters were determined. According to the theory model developed for the $4 f-4 f$ transitions, the calculus to obtain the intensity parameters $\left(\Omega_{2}\right.$ and $\left.\Omega_{4}\right)$, called Judd-Ofelt parameters, are determined through the transition band intensities of the ${ }^{5} D_{0}$ to the ${ }^{7} F_{J}(J=2$ and 4$)$ levels. The luminescence intensity (I) of the $\mathrm{Eu}(\mathrm{III})$ ion transitions is given by Eq. (1):

$I_{0 \rightarrow J}=\hbar \omega_{0 J} \cdot A_{0 \rightarrow J} \cdot N_{0}=S_{0 \rightarrow J}$

where $A_{0 \rightarrow J}$ is the Einstein spontaneous emission coefficient, $N_{0}$ is the population of the emitter level $\left({ }^{5} \mathrm{D}_{0}\right)$, and $\hbar \omega_{0 J}$ is the transition energy. $A_{0 \rightarrow J}$ is the Einstein spontaneous emission coefficient (for the ${ }^{5} \mathrm{D}_{0} \rightarrow{ }^{7} \mathrm{~F}_{2}$ and ${ }^{5} \mathrm{D}_{0} \rightarrow{ }^{7} \mathrm{~F}_{4}$ electronic transitions). For $A_{0 \rightarrow J}$ calculation, the bellow equation is considered [48]:

$A_{0 \rightarrow J}=\frac{\sigma_{0 \rightarrow 1}}{S_{0 \rightarrow 1}} \cdot \frac{S_{0 \rightarrow J}}{\sigma_{0 \rightarrow J}} \cdot A_{0 \rightarrow 1}$

where $\sigma_{0 \rightarrow 1}$ and $\sigma_{0 \rightarrow J}$ correspond to energy baricenters of ${ }^{5} \mathrm{D}_{0} \rightarrow{ }^{7} \mathrm{~F}_{1}$ and ${ }^{5} \mathrm{D}_{0} \rightarrow{ }^{7} \mathrm{~F}_{\mathrm{J}}$, respectively. $S_{0 \rightarrow 1}$ and $\S_{0 \rightarrow J}$ are emission curve areas corresponding to ${ }^{5} \mathrm{D}_{0} \rightarrow{ }^{7} \mathrm{~F}_{1}$ and ${ }^{5} \mathrm{D}_{0} \rightarrow{ }^{7} \mathrm{~F}_{\mathrm{J}}$ transitions, respectively [49]. As known, the magnetic dipole allowed ${ }^{5} \mathrm{D}_{0} \rightarrow{ }^{7} \mathrm{~F}_{1}$ transition was taken as reference [50], since $A_{0 \rightarrow 1}$ rate is almost insensitive to chemical environment changes around the $\mathrm{Eu}(\mathrm{III})$ ion with $A_{0 \rightarrow 1} \cong 50 \mathrm{~s}^{-1}$. The experimental intensity parameters $\Omega_{\lambda}(\lambda=2$ and 4) are estimated from the ${ }^{5} D_{0} \rightarrow{ }^{7} F_{2}$ and ${ }^{5} D_{0} \rightarrow{ }^{7} F_{4}$ transitions, respectively, in the emission spectrum of the Eu(III) complex. The experimental intensities parameters were calculated from the spontaneous emission coefficients $\left(A_{0 \rightarrow J}\right)$, according to the following expression [51]:

$\Omega_{\lambda}=\frac{3 \hbar c^{3} A_{0 \rightarrow J}}{4 e^{2} \omega^{3} \chi<{ }^{7} F_{J}\left\|U^{(\lambda)}\right\|^{5} D_{0}>^{2}}$

where $\chi$ is the Lorentz local field correction term, given by $\chi=\frac{n(n+2)^{2}}{9}$ and $\left\langle{ }^{7} F_{J}\left\|U^{(\lambda)}\right\|^{5} D_{0}>^{2}\right.$ is a squared reduced matrix element with value of 0.0032 for the ${ }^{5} \mathrm{D}_{0} \rightarrow{ }^{7} \mathrm{~F}_{2}$ transition and 0.0023 for the ${ }^{5} \mathrm{D}_{0} \rightarrow{ }^{7} \mathrm{~F}_{4}$ one and $\Omega_{\lambda}$ are the Judd-Ofelt intensity parameters $[52,53]$. The refraction index $(n)$ has been assumed equal to 1.5. In this work, the ${ }^{5} D_{0} \rightarrow{ }^{7} F_{6}$ transition was not observed experimentally; consequently, the experimental $\Omega_{6}$ parameter could not be estimated. In particular, $\Omega_{2}$ is more sensitive to symmetry and sequence of ligands fields. Based on the emission spectrum and lifetime of ${ }^{5} \mathrm{D}_{0}$ emitting level, the emission quantum efficiency $(\eta)$ of europium ion in compound $\left[\mathrm{Eu}_{2}(\mathrm{hcin})_{6}(\text { phen })_{2}\right] \mathbf{1}$ was determined. Initially the emission coefficients $\mathrm{A}_{02}$ and $\mathrm{A}_{04}$ corresponding to ${ }^{5} \mathrm{D}_{0} \rightarrow{ }^{7} \mathrm{~F}_{2}$ and ${ }^{5} \mathrm{D}_{0} \rightarrow{ }^{7} \mathrm{~F}_{4}$ transitions, respectively, were calculated according to the Eq. (2). Considering the ratio between the emitting state lifetime and total decay rate, $\left(A_{\text {total }}=1 / \tau=A_{\text {rad }}+A_{\text {nrad }}\right)$, the $\eta$ value can be calculated by the Eq. (4) [54]:

$\eta=\frac{A_{\text {rad }}}{A_{\text {rad }}+A_{\text {nrad }}}$

The values of spectroscopic properties as $\boldsymbol{\Omega}_{\lambda}$ intensity parameters $(\lambda=2$ and 4$)$, radiative $\left(A_{\text {rad }}\right)$ and nonradiative $\left(A_{\text {nrad }}\right)$ decay rates, luminescence lifetimes $(\tau)$ and quantum efficiency $(\eta)$ of $\left[\mathrm{Eu}_{2}(\text { hcin })_{6}(\text { phen })_{2}\right] \mathbf{1}$ complex, together with those for complex $\left[\mathrm{Eu}_{2}(\mathrm{hcin})_{6}(\mathrm{bpy})_{2}\right][20]$ are shown in Table 4. The signal intensities of these complexes are compared in Fig. 7. Additionally, from the comparison between the emission spectra obtained at 300

Table 4

Photoluminescence data of $\left[\mathrm{Eu}_{2}(\mathrm{hcin})_{6}(\text { phen })_{2}\right] \mathbf{1}$ complex and $\left[\mathrm{Eu}_{2}(\mathrm{hcin})_{6}(\mathrm{bpy})_{2}\right][20]$ complex, both in the solid state.

\begin{tabular}{|c|c|c|c|c|c|c|c|}
\hline Eu(III) complexes & $\Omega_{2}\left(10^{-20} \mathrm{~cm}^{2}\right)$ & $\Omega_{4}\left(10^{-20} \mathrm{~cm}^{2}\right)$ & $A_{\text {rad }}\left(\mathrm{s}^{-1}\right)$ & $A_{\text {nrad }}\left(\mathrm{s}^{-1}\right)$ & $A_{\text {total }}\left(\mathrm{s}^{-1}\right)$ & $\tau(\mathrm{ms})$ & $\eta(\%)$ \\
\hline$\left[\mathrm{Eu}_{2}(\text { hcin })_{6}(\text { phen })_{2}\right]$ & 7.91 & 8.33 & 383.5 & 145.6 & 529.1 & $1.89^{\mathrm{a}}$ & 72 \\
\hline$\left[\mathrm{Eu}_{2}(\text { hcin })_{6}(\text { bpy })_{2}\right]$ Ref. [20] & 7.17 & 8.96 & 412.5 & 204.7 & 617.2 & $1.62^{\mathrm{a}}$ & 67 \\
\hline
\end{tabular}

a Error: $\pm 0.001 \mathrm{~ms}$. 

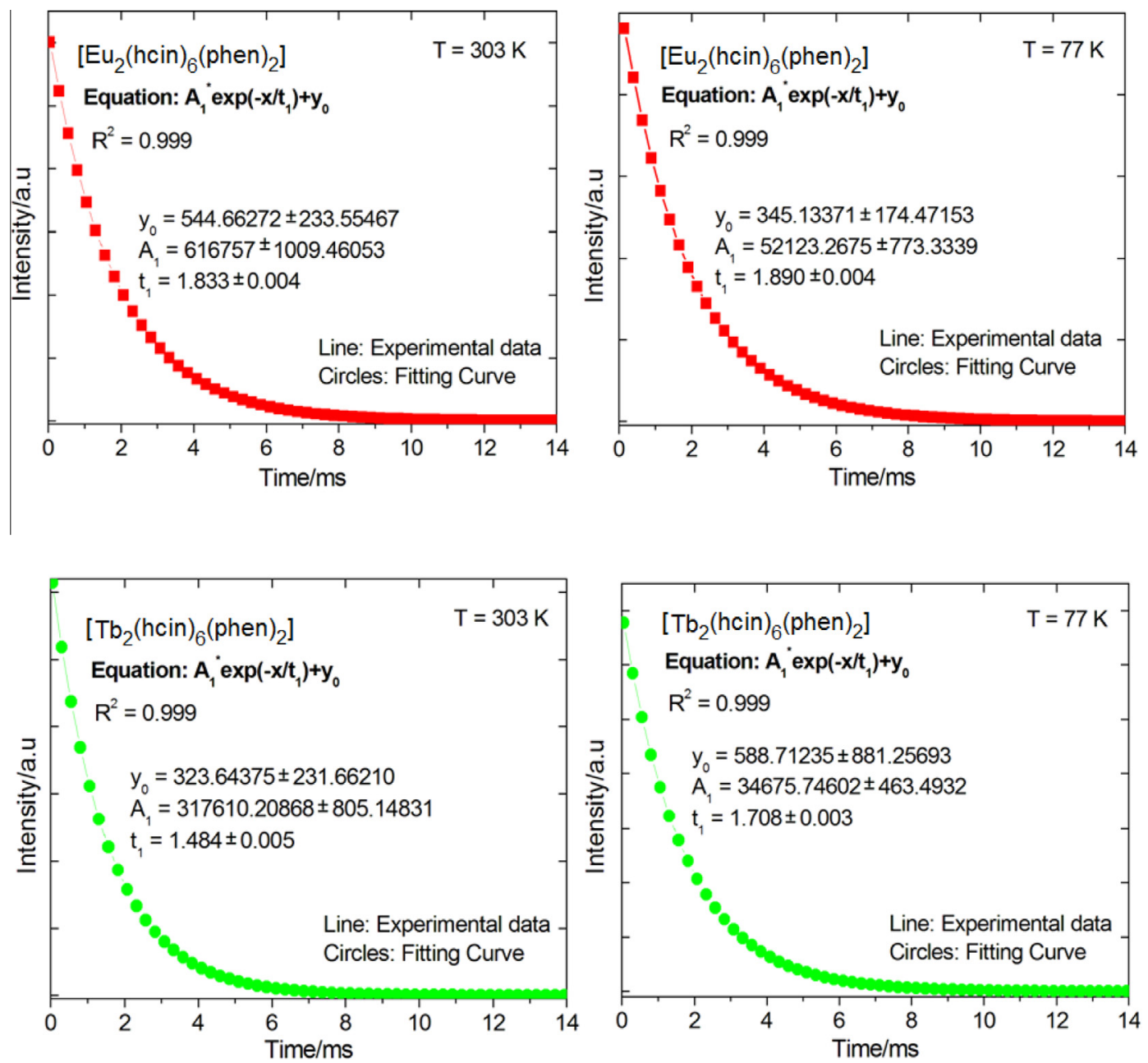

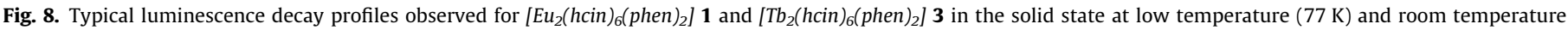
$(303 \mathrm{~K})$, with excitation at $330 \mathrm{~nm}$.

(Fig. 5b) and $77 \mathrm{~K}$ (Fig. 7), a better resolution of spectral lines at low temperature with significant difference due to Stark levels was observed. In this spectrum the transitions from ${ }^{5} \mathrm{D}_{1}$ excited state to ${ }^{7} \mathrm{~F}_{0},{ }^{7} \mathrm{~F}_{1}$ and ${ }^{7} \mathrm{~F}_{2}$ states can be also observed (inset in Fig. 9). Such transitions exhibit extremely low intensity because ${ }^{5} D_{0}$ and ${ }^{5} D_{1}$ levels have small energy gap, and so, the energy transfer ${ }^{5} \mathrm{D}_{1} \rightarrow{ }^{5} \mathrm{D}_{0}$ is preferred in relation to electronic transitions ${ }^{5} \mathrm{D}_{1} \rightarrow{ }^{7} \mathrm{~F}_{\mathrm{J}}(\mathrm{J}=0-6)$.

The intensity parameters values $\left(\Omega_{2}\right.$ and $\left.\Omega_{4}\right)$ for the $\left[E u_{2}\right.$ (hcin $)_{6}$ (phen $\left.)_{2}\right]$ complex are similar to those found for $\left[\mathrm{Eu}_{2}(\text { hcin })_{6}\right.$ (bpy) $)_{2}$ ] complex (Table 4) leading to the conclusion that the local geometry and the ligating atoms polarizabilities are relatively similar in both complexes. The $\Omega_{4}$ parameter is influenced by the ion-ligand and ion-ion bond distances. The smaller emitter ions distance the greater the value $\Omega_{4}$, indicating that there are longrange interactions between luminescent ions. In $\left.\left[\mathrm{Eu}_{2}(\text { hcin })_{6} \text { (phen }\right)_{2}\right]$ complex the Eu...Eu distance of $4.063 \AA$ is slightly larger than the Eu. . Eu distance of $3.951 \AA$ in $\left[\operatorname{Eu}_{2}(\text { hcin })_{6}(\text { bpy })_{2}\right]$. These values are consistent with those $\Omega_{4}$ values found for the complexes: 8.33 for the $\left[E u_{2}(\text { hcin })_{6}(\text { phen })_{2}\right]$ and 8.96 for the $\left[E u_{2}(\text { hcin })_{6}(\text { bpy })_{2}\right]$. The ${ }^{5} \mathrm{D}_{0} \rightarrow{ }^{7} \mathrm{~F}_{0}$ transition energy can be correlated with the covalence degree of Eu-L bonds and the red shift of this transition is due to the nephelauxetic effect [55-57]. In order to promote a comparison between $\left[\mathrm{Eu}_{2}(\mathrm{hcin})_{6}(\mathrm{bpy})_{2}\right]$ and $\left[\mathrm{Eu}_{2}(\mathrm{hcin})_{6}(\text { phen })_{2}\right]$ complexes, the ${ }^{5} \mathrm{D}_{0} \rightarrow{ }^{7} \mathrm{~F}_{0}$ transition centroid energy was determined and these values are: $580 \mathrm{~nm}\left(17,241 \mathrm{~cm}^{-1}\right)$ for $\left[\mathrm{Eu}_{2}(\operatorname{cin})_{6}(\text { bpy })_{2}\right]$ complex and

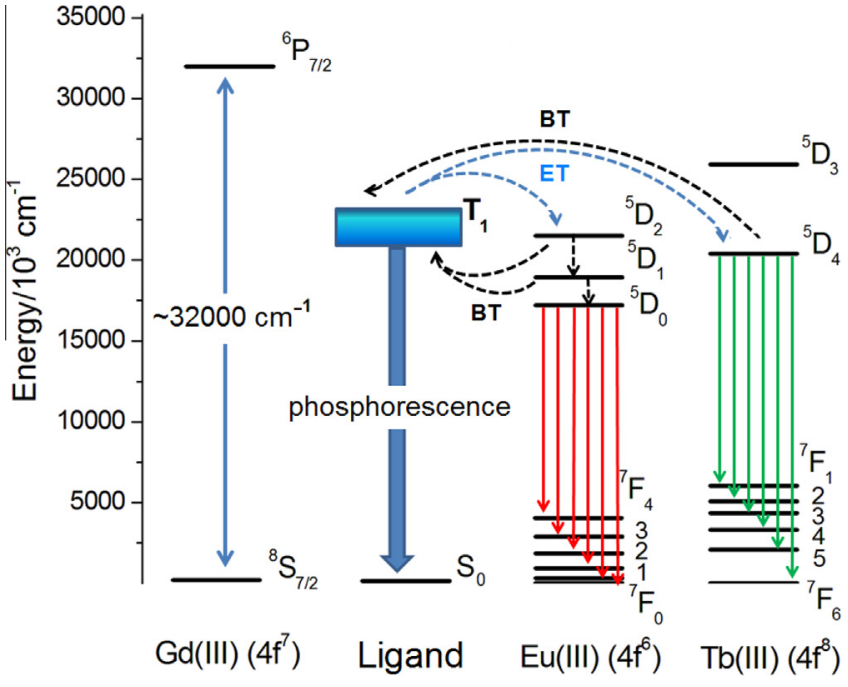

Fig. 9. Schematic energy level diagram and the possible energy transfer process in the systems of $\left[\mathrm{Eu}_{2}(\mathrm{hcin})_{6}(\text { phen })_{2}\right] \mathbf{1}$ and $\left[\mathrm{Tb}_{2}\right.$ (hcin) $\left.{ }_{6}(\text { phen })_{2}\right] \mathbf{3 .} \mathrm{T}_{1}$, the first excited triplet state; BT, back-energy transfer; ET, energy transfer.

$582 \mathrm{~nm}\left(17,182 \mathrm{~cm}^{-1}\right)$ for $\left[\mathrm{Eu}_{2}(\text { hcin })_{6}(\text { phen })_{2}\right] \mathbf{1}$ (Fig. S6 in Supplementary Material). These results indicate that the complexes covalence depends on the ancillary ligand nature, being higher for 


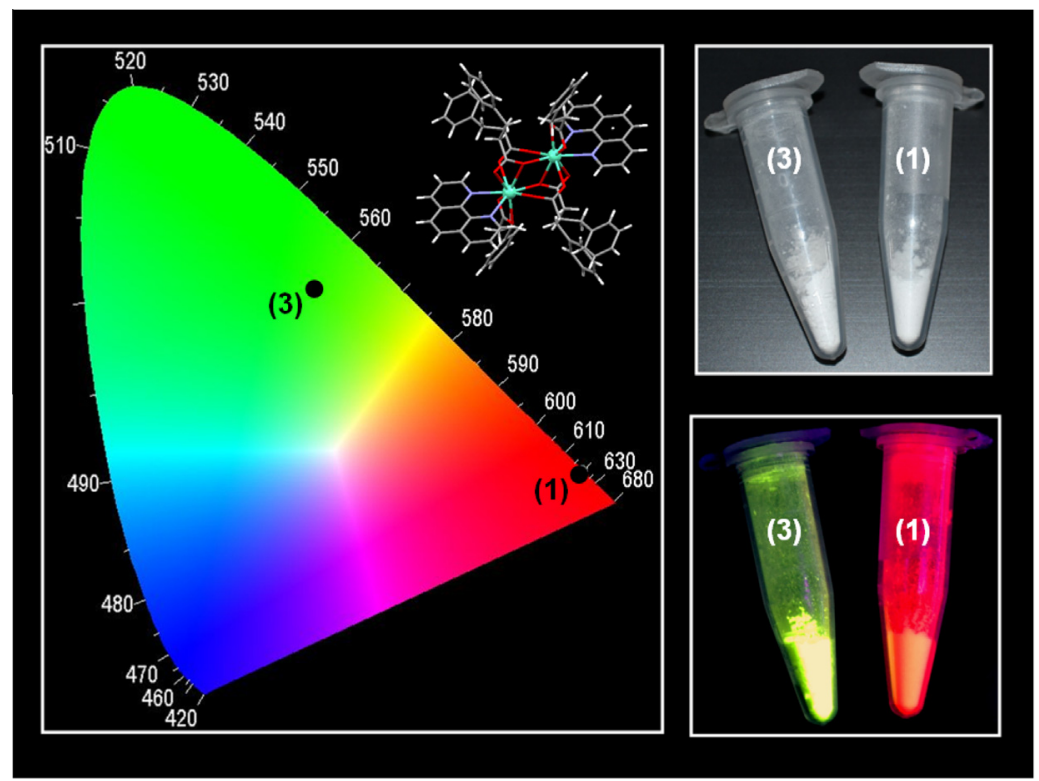

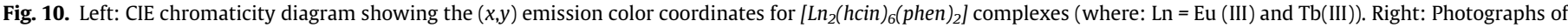

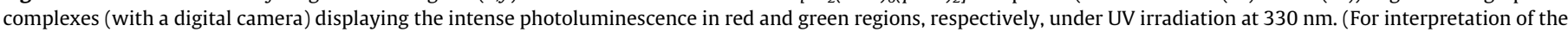
references to colour in this figure legend, the reader is referred to the web version of this article.)

$\mathrm{L}=1,10$ phenanthroline (phen) than for 2,2'-bipyridine (bpy), although both complexes present close $\Omega_{2}$ intensity parameters values. Similar results were reported for $\left[E u\left(E t_{2} N C S_{2}\right)_{3} b p y\right]$ and $\left[E u\left(E t_{2}-\right.\right.$ $\left.\mathrm{NCS}_{2}\right)_{3}$ phen] complexes [58] and for several other complexes in chloroformic solutions [59]. Complexes 1 and $\mathbf{3}$ luminescence lifetimes $(\tau)$ in the solid state have been determined at 300 and $77 \mathrm{~K}$, under excitation at $330 \mathrm{~nm}$, with emission monitored at ${ }^{5} \mathrm{D}_{0} \rightarrow{ }^{7} \mathrm{~F}_{2}$ and ${ }^{5} \mathrm{D}_{4} \rightarrow{ }^{7} \mathrm{~F}_{5}$ transitions for $\mathrm{Eu}(\mathrm{III})$ and $\mathrm{Tb}(\mathrm{III})$, respectively. Each of the decay curves (Fig. 8) follows monoexponential decay law, and the equation intensity $=A_{1} \cdot \exp \left(-x / t_{1}\right)+y_{0}$ was used for fitting the fluorescence decay curves.

These data are also consistent with only one symmetry site for both complexes, in agreement with $\mathrm{Eu}(\mathrm{III})$ complex emission spectrum and X-ray diffraction analysis. The lifetimes values, at $303 \mathrm{~K}$, are $1.83 \mathrm{~ms}$ for $\left[\mathrm{Eu}_{2}(\mathrm{hcin})_{6}(\text { phen })_{2}\right] \mathbf{1}$ and $1.48 \mathrm{~ms}$ for $\left[\mathrm{Tb}_{2}(\text { hcin })_{6}\right.$ $\left.(\text { phen })_{2}\right]$ 3,and at liquid nitrogen temperature $(77 \mathrm{~K})$ are greater, 1.89 and $1.70 \mathrm{~ms}$, respectively. This fact is related to the decrease in vibrational contributions caused by the decrease in the temperature. As expected, the highest lifetime values obtained for the compounds are due the absence of water in first coordination sphere, in accordance with FTIR and thermal analysis data. The emission lifetime value for the $\left[\mathrm{Eu}_{2}(\text { hcin })_{6}(\text { phen })_{2}\right] \mathbf{1}$ complex ( $\tau=1.89 \mathrm{~ms}$ ) is greater than the value obtained for the $\left[E u_{2}(h c i n)_{6}\right.$ (bpy) $)_{2}$ ( $\left.\tau=1.62 \mathrm{~ms}\right)$ [20], reflecting on a greater quantum efficiency $(\eta)$ value for complex $\mathbf{1}$, containing phen ligand. The stronger luminescence observed for $\left[\mathrm{Eu}_{2} \text { (hcin) }\right)_{6}$ (phen $\left.)_{2}\right]$ can be associated to a greater structural rigidity of phen ligand, allowing a better energy transfer. The rigid structure restricts the thermal vibration of the ligand and reduces the energy loss by radiationless decay. Yang et al. [60] reported similar fact, comparing a more intense emission for $\left[\mathrm{Eu}(\mathrm{tta})_{3}(\right.$ phen $\left.)\right]$ than for $\left[\mathrm{Eu}(\mathrm{tta})_{3}(\mathrm{bpy})\right]$. Also, the optimum energy gap between the triplet $\left(\mathrm{T}_{1}\right)$ energy levels and ${ }^{5} \mathrm{D}_{0,1}$ states in $\left[\mathrm{Eu}_{2}(\text { hcin })_{6}(\text { phen })_{2}\right]$ complex in relation to the $\left[\mathrm{Eu}_{2}(\text { hcin })_{6}(\text { bpy })_{2}\right]$ complex (according to the phosphorescence spectra) provides high values of intramolecular energy transfer minimizing the backenergy transfer process. According to the above experimental results, the schematic energy level diagram and the most probable channels for the intramolecular energy transfer process are shown in Fig. 9.
The $\left[\mathrm{Ln}_{2}(\text { hcin })_{6}(\text { phen })_{2}\right](\mathrm{Ln}=\mathrm{Eu}(\mathbf{1})$ and $\mathrm{Tb}(\mathbf{3}))$ complexes show $(x, y)$ color coordinates for $\mathrm{Eu}(\mathrm{III})(0.689,0.308)$ and $\mathrm{Tb}(\mathrm{III})(0.323$, $0.557)$ in the red and green regions of the CIE chromaticity diagram (Commission Internationale de l'Eclairage), respectively, as exhibited in Fig. 10. Therefore, these complexes act as light conversion molecular devices (LCMDs) producing intense monochromatic emission colors and can be applied in bicolor devices.

\section{Conclusions}

In this work, new binuclear complexes of lanthanide ions with the hydrocinnamate ligand are presented. The complexes, of general formula $\left[\mathrm{Eu}_{2}(\text { hcin })_{6}(\text { phen })_{2}\right], \quad(\mathrm{Ln}=\mathrm{Eu} \mathrm{1}$; Gd 2; Tb 3; hcin = hydrocinnamate anion; phen $=1,10$-phenanthroline) were synthesized, fully characterized and their photophysical properties were studied in detail. The crystal structures of complexes were solved and refined using powder X-ray diffraction patterns, revealing that all compounds are isostructural and that each lanthanide ion is nine coordinated by oxygen and nitrogen atoms to form distorted tricapped trigonal-prismatic coordination polyhedron. According to the photoluminescence study, the phosphorescence broad bands from ligands are not present in any spectra, which suggest that the intramolecular ligand-to-metal energy transfer is efficient. This fact was reinforced by measuring the first triplet state $\left(\mathrm{T}_{1}\right)$ energies of the organic ligands that is above ${ }^{5} \mathrm{D}_{0} \mathrm{Eu}(\mathrm{III})$ and ${ }^{5} \mathrm{D}_{4} \mathrm{~Tb}$ (III) energy levels. The values of spectroscopic properties as $\Omega_{\lambda}$ intensity parameters ( $\lambda=2$ and 4 ), radiative $\left(A_{\text {rad }}\right)$ and nonradiative $\left(A_{\text {nrad }}\right)$ decay rates, luminescence lifetimes $(\tau)$ and quantum efficiency $(\eta)$ of $\left[\mathrm{Eu}_{2}(\text { hcin })_{6}(\text { phen })_{2}\right] \mathbf{1}$ complex was calculated from the experimental data and compared to those values for the similar complex $\left[\mathrm{Eu}_{2}(\mathrm{hcin})_{6}(\mathrm{bpy})_{2}\right]$ previously reported. The $\left[\mathrm{Eu}_{2}(\mathrm{hcin})_{6}(-\right.$ phen $)_{2}$ ] 1 displays a quantum yield about $73 \%$ suggesting that the system can act as efficient light-conversion molecular devices (LCMDs). According to our studies in the binuclear hydrocinnamates, the phen ligand could be a better candidate on sensitizing $\mathrm{Eu}(\mathrm{III})$ ion luminescence than bpy ligand. These results have motivated us to synthesize and develop new highly photoluminescent binuclear hydrocinnamates of lanthanides given a scarcity of these 
compounds in the literature. This class of compounds has shown great promise in the development of electroluminescent devices.

\section{Acknowledgments}

The authors thank the Brazilian agencies CNPq (304657/2013-1), CAPES, FAPESP and FAPEMIG (CEX-APQ 00808-13). The authors are also very grateful to Dr. Luiz Fernando Brum Malta (Instituto de Química da Universidade Federal do Rio de Janeiro) for thermal analysis measurements.

\section{Appendix A. Supplementary material}

CCDC 1420383-1420385 contain the supplementary crystallographic data for the compound 1-3. These data can be obtained free of charge from The Cambridge Crystallographic Data Centre via www.ccdc.cam.ac.uk/data_request/cif. Supplementary data associated with this article can be found, in the online version, at http://dx.doi.org/10.1016/j.ica.2015.11.009.

\section{References}

[1] J.C.G. Bünzli, G.R. Choppin (Eds.), Lanthanide Probes in Life, Chemical and Earth Sciences - Theory and Practice, Elsevier, Amsterdam, 1989 (Chapter 7).

[2] F.S. Richardson, Chem. Rev. 82 (1982) 541.

[3] H. Mikola, H. Takalo, I. Hemmila, Bioconjug. Chem. 6 (1995) 235.

[4] J. Rocha, L.D. Carlos, F.A.A. Paz, D. Ananias, Chem. Soc. Rev. 40 (2011) 926.

[5] M.A. Katkova, T.V. Balashova, V.A. Ilichev, A.N. Konev, N.A. Isachenkov, G.K. Fukin, S.Y. Ketkov, M.N. Bochkarev, Inorg. Chem. 49 (2010) 5094

[6] M.G. Lahoud, L.F. Marques, P.B. Silva, C.A. Jesus, C.C. Silva, J.A. Ellena, R.S. Freitas, M.R. Davolos, R.G.C. Frem, Polyhedron 54 (2013) 1.

[7] D. Parker, Aust. J. Chem. 64 (2011) 239.

[8] L.F. Marques, C.C. Correa, S.J.L. Ribeiro, M.V. dos Santos, J.D.L. Dutra, R.O. Freire, F.C. Machado, J. Solid State Chem. 227 (2015) 68.

[9] N. Sabbatini, M. Guardigli, J.M. Lehn, Coord. Chem. Rev. 123 (1993) 201.

[10] G. Zucchi, V. Murugesan, D. Tondelier, D. Aldakov, T. Jeon, F. Yang, P. Thuery, M Ephritikhine, B. Geffroy, Inorg. Chem. 50 (2011) 4851.

[11] H.F. Li, P.F. Yan, P. Chen, Y. Wang, H. Xu, G.M. Li, Dalton Trans. 41 (2012) 900.

[12] Y. Wang, Y. Song, Z.R. Pan, Y.Z. Shen, Z. Hu, Z.J. Guo, H.G. Zheng, Dalton Trans. 41 (2008) 5588

[13] L.F. Marques, M.V. dos Santos, S.J.L. Ribeiro, E.E. Castellano, F.C. Machado, Polyhedron 38 (2012) 149.

[14] C. Daiguebonne, N. Kerbellec, G. Ouillou, J.C. Bunzli, F. Gumy, L. Catala, T. Mallah, A. Nudebrand, Y. Gerault, K. Bernot, G. Calvez, Inorg. Chem. 47 (2008) 3700 .

[15] C.W. Moss, M.A. Lambert, D.J. Goldsmith, Appl. Microbiol. 19 (2) (1970) 375.

[16] S.M. Korneev, Synthesis 45 (8) (2013) 1000.

[17] R. Najjar, W. de Oliveira, J.B. Carducci, Polyhedron 8 (1989) 1157.

[18] E. Dubler, U.K. Haring, K.H. Scheller, P.H. Baltzer, Inorg. Chem. 23 (1984) 3785.

[19] L.F. Marques, A.A.B.C. Junior, C.C. Correa, M.G. Lahoud, R.R. da Silva, S.J.L. Ribeiro, F.C. Machado, J. Photochem. Photobiol. A: Chem. 252 (2013) 69.

[20] L.F. Marques, C.C. Correa, H.C. Garcia, S.J.L. Ribeiro, J.D.L. Dutra, R.O. Freire, F.C Machado, J. Lumin. 148 (2014) 307.
[21] S. Biju, D.B. Ambili, M.L.P. Reddy, B.M. Kariuki, Inorg. Chem. 45 (2006) 10651.

[22] W.J. Chai, W.X. Lin, X.J. Sun, T. Ren, X.Y. Shi, J. Lumin. 131 (2011) 225.

[23] A.A. Coelho, J. Appl. Crystallogr. 36 (2003) 86.

[24] TOPAS-R (2009). Version 4.2, General profile and structure analysis software for powder diffraction data, Bruker AXS, Karlsruhe, Germany.

[25] G.S. Pawley, J. Appl. Crystallogr. 14 (1981) 357.

[26] A. Coelho, J. Appl. Crystallogr. 22 (2000) 899.

[27] A.L. Spek, Acta Crystallogr. D65 (2009) 148.

[28] Y.V. Nelyubina, A.A. Korlyukov, K.A. Lyssenko, Mendeleev Commun. 24 (2014) 286.

[29] U. Das, B. Chattopadhyay, M. Mukherjee, A.K. Mukherjee, Cryst. Growth Des. 12 (2012) 466.

[30] R.A. Young, "The Rietveld Method", IUCr Monograph N.5 Oxford University Press, New York, 1981.

[31] S.A. da Silva, C.Q.F. Leite, F.R. Pavan, N. Masciocchi, A. Cuin, Polyhedron 79 (2014) 170.

[32] S.A. da Silva, N. Masciocchi, A. Cuin, Powder Diffr. 29 (3) (2014) 300.

[33] T.C. Amaral, G.S.G. Carvalho, A.D. da Silva, P.P. Corbi, N. Masciocchi, E.E. Castellano, A. Cuin, J. Coord. Chem. 67 (8) (2014) 1380.

[34] N. Masciocchi, A. Sironi, J. Chem. Soc., Dalton Trans. (1997) 4643.

[35] E. Keller, Chem. unserer Zeit 20 (1986) 178.

[36] G.B. Deacon, C.M. Forsyth, P.C. Junk, M. Hilder, S.G. Leary, C. Bromant, I. Pantenburg, G. Meyer, B.W. Skelton, A.H. White, Z. Anorg. Allg. Chem. 634 (2007) 91.

[37] A. de Bettencourt-Dias, S. Viswanathan, Dalton Trans. 34 (2006) 4093.

[38] X. Li, Y.Q. Zou, B. Zheng, H.M. Hu, Acta Crystallogr., Sect. C 60 (2004) 197-199.

[39] L.-Z. Cai, W.-T. Chen, M.-S. Wang, G.-C. Guo, J.-S. Huang, Inorg. Chem. Commun. 7 (2004) 611.

[40] G.B. Deacon, R.J. Phillips, Coord. Chem. Rev. 33 (1980) 227.

[41] J. Vícha, C. Foroutan-Nejad, T. Pawlak, M.L. Munzarová, M. Straka, R. Marek, J. Chem. Theory Comput. 11 (2015) 1509.

[42] S. Aime, I. Bertini, C. Luchinat, Coord. Chem. Rev. 150 (1996) 221.

[43] R.J. Smernik, J.M. Oades, J. Environ. Qual. 31 (2002) 414.

[44] S. Tobita, M. Arakawa, I. Tanaka, J. Phys. Chem. 89 (1985) 5649.

[45] S. Tobita, M. Arakawa, I. Tanaka, J. Phys. Chem. 88 (1984) 2697.

[46] P. A. Tanner, in Lanthanide Luminescence. Photophysical, Analytical and Biological Aspects, ed. P. Hanninen and H. Harma, Springer, Berlin, 2011, ch. 7, pp. 183-233.

[47] M. Latva, H. Takalo, V.M. Mukkala, C. Matachescu, J.C. Rodriguez-Ubis, J. Kanakare, J. Lumin. 75 (1997) 149.

[48] C.D. Donegá, S. Alves Jr., G.F. de Sá, J. Alloys Compd. 250 (1997) 422-426. Lausanne.

[49] E.E.S. Teotonio, G.M. Fett, H.F. Brito, W.M. Faustino, G.F. de Sa, M.C.F.C. Felinto, R.H.A. Santos, J. Lumin. 128 (2008) 190.

[50] D.B. Ambili, S. Raj, M.L.P. Biju, Inorg. Chem. 47 (2008) 8091.

[51] O.L. Malta, H.F. Brito, J.F.S. Menezes, J. Lumin. 75 (1997) 255.

[52] B.R. Judd, Phys. Rev. 127 (1962) 750.

[53] G.S. Ofelt, J. Chem. Phys. 37 (1962) 511.

[54] G.F. de Sá, O.L. Malta, C.M. Donegá, A.M. Simas, R.L. Longo, P.A. Santa-Cruz, E.F. da Silva Jr., Coord. Chem. Rev. 196 (2000) 165-195.

[55] O.L. Malta, H.J. Batista, L.D. Carlos, Chem. Phys. 282 (2002) 21.

[56] R.A.S. Ferreira, S.S. Nobre, C.M. Granadeiro, H.I.S. Nogueira, L.D. Carlos, O.L. Malta, J. Lumin. 121 (2006) 561.

[57] A.P. Souza, L.C.V. Rodrigues, H.F. Brito, S. Alves Jr., O.L. Malta, J. Lumin. 130 (2010) 181.

[58] W.M. Faustino, O.L. Malta, E.E.S. Teotônio, H.F. Brito, A.M. Simas, G.F. de Sá, J. Phys. Chem. A 110 (2006) 2510.

[59] C.Y. Su, M.Y. Tan, N. Tang, W. Liu, X. Wang, J. Coord. Chem. 38 (1996) 207.

[60] Y.S. Yang, M.L. Gong, Y.Y. Li, H.Y. Lei, S.L. Wu, J. Alloys Compd. 112 (1994) 207. 